\title{
Saponins in Chinese Herbal Medicine Exerts Protection in Myocardial Ischemia-Reperfusion Injury: Possible Mechanism and Target Analysis
}

\section{OPEN ACCESS}

Edited by:

Da-zhuo Shi,

China Academy of Chinese Medical

Sciences, China

Reviewed by:

Jun Peng,

Fujian University of Traditional Chinese

Medicine, China

Lanping Guo,

China Academy of Chinese Medical

Sciences, China

*Correspondence:

Guibo Sun

sunguibo@126.com

Xiaobo Sun

sun_xiaobo163@163.com

Specialty section: This article was submitted to

Ethnopharmacology,

a section of the journal

Frontiers in Pharmacology

Received: 09 June 2020 Accepted: 28 October 2020 Published: 14 January 2021

Citation:

Wang R, Wang $M$, Zhou J, Wu D, Ye J, Sun $G$ and Sun $X$ (2021) Saponins in

Chinese Herbal Medicine Exerts

Protection in Myocardial Ischemia-Reperfusion Injury: Possible

Mechanism and Target Analysis.

Front. Pharmacol. 11:570867.

doi: 10.3389/fphar.2020.570867

\author{
Ruiying Wang ${ }^{1,2,3,4,5}$, Min Wang ${ }^{1,2,3,4,5}$, Jiahui Zhou ${ }^{1,2,3,4,5}$, Daoshun Wu $\mathbf{u}^{1,2,3,4,5}$, \\ Jingxue $\mathrm{Ye}^{1}$, Guibo Sun ${ }^{1,2,3,4,5 *}$ and Xiaobo Sun ${ }^{1,2,3,4,5 *}$
}

${ }^{1}$ Institute of Medicinal Plant Development, Chinese Academy of Medical Sciences and Peking Union Medical College, Beijing, China, ${ }^{2}$ Beijing Key Laboratory of Innovative Drug Discovery of Traditional Chinese Medicine (Natural Medicine) and Translational Medicine, Institute of Medicinal Plant Development, Peking Union Medical College and Chinese Academy of Medical Sciences, Beijing, China, ${ }^{3}$ Key Laboratory of Bioactive Substances and Resources Utilization of Chinese Herbal Medicine, Ministry of Education, Institute of Medicinal Plant Development, Chinese Academy of Medical Sciences and Peking Union Medical College, Beijing, China, ${ }^{4}$ Key Laboratory of Efficacy Evaluation of Chinese Medicine Against Glycolipid Metabolic Disorders, State Administration of Traditional Chinese Medicine, Institute of Medicinal Plant Development, Peking Union Medical College and Chinese Academy of Medical Sciences, Beijing, China, ${ }^{5}$ Key Laboratory of New Drug Discovery Based on Classic Chinese Medicine Prescription, Chinese Academy of Medical Sciences, Beijing, China

Myocardial ischemia is a high-risk disease among middle-aged and senior individuals. After thrombolytic therapy, heart tissue can potentially suffer further damage, which is called myocardial ischemia-reperfusion injury (MIRI). At present, the treatment methods and drugs for MIRI are scarce and cannot meet the current clinical needs. The mechanism of $\mathrm{MIRI}$ involves the interaction of multiple factors, and the current research hotspots mainly include oxidative stress, inflammation, calcium overload, energy metabolism disorders, pyroptosis, and ferroptosis. Traditional Chinese medicine (TCM) has multiple targets and few toxic side effects; clinical preparations containing Panax ginseng C. A. Mey., Panax notoginseng (Burk.) F. H. Chen, Aralia chinensis L., cardioprotection, and other Chinese herbal medicines have been used to treat patients with coronary heart disease, angina pectoris, and other cardiovascular diseases. Studies have shown that saponins are the main active substances in TCMs containing Panax ginseng C. A. Mey., Panax notoginseng (Burk.) F. H. Chen, Aralia chinensis L., and Radix astragali. In the present review, we sorted the saponin components with anti-MIRI effects and their regulatory mechanisms. Each saponin can play a cardioprotective role via multiple mechanisms, and the signaling pathways involved in different saponins are not the same. We found that more active saponins in Panax ginseng C. A. Mey. are mainly dammar-type structures and have a strong regulatory effect on energy metabolism. The highly active saponin components of Aralia chinensis L. are oleanolic acid structures, which have significant regulatory effects on calcium homeostasis. Therefore, saponins in Chinese herbal medicine provide a broad application prospect for the development of highly effective and low-toxicity antiMIRI drugs.

Keywords: saponins, traditional Chinese medicine, myocardial ischemia-reperfusion injury, mechanism, ginsenosides, aralia saponins 


\section{INTRODUCTION}

To date, revascularization, such as thrombolysis, is an effective method for the treatment of ischemic cardiomyopathy in patients with acute myocardial infarction (Yang et al., 2018). However, reperfusion can still cause other damage to the myocardium, which greatly reduces the advantages of reperfusion therapy (Bell and Yellon, 2011). Therefore, myocardial ischemia-reperfusion injury (MIRI) is a current clinical problem that needs urgent attention. MIRI involves a variety of classical mechanisms, including oxidative stress, inflammation, calcium overload, and mitochondrial damage (Turer and Hill, 2010). In recent years, there has been an increasing number of studies on cell pyroptosis, ferroptosis, and autophagy during MIRI (Jia et al., 2019; Li C. Y. et al., 2020). Over the past three decades, methods to reduce MIRI have been in development and have been used in clinical treatments (Garcia-Dorado et al., 2014). The treatment methods mainly include non-pharmacological interventions (ischemic pre-conditioning) and pharmaceutical treatments (Ibanez et al., 2015). At present, several drugs are effective in MIRI animal models, but their clinical use is not ideal, which may be due to the complex pathological mechanism of MIRI.

Traditional Chinese medicines (TCM) has a holistic treatment concept, and has the advantages of multiple targets, multiple links, and multiple approaches. In the field of TCM, the etiology of MIRI involves deficiency of qi, blood stasis, and phlegm. The clinical treatment is often based on TCM and compound preparations with the effects of replenishing qi and nourishing yin, warming the heart, promoting blood circulation and removing blood stasis, and expelling phlegm (Liu et al., 2013). TCM containing a large amount of saponins include Panax ginseng C. A. Mey., Panax notoginseng (Burk.) F.H. Chen, Panax quinquefolium L., Aralia chinensis L., and Radix astragali (Tu et al., 2013; Aravinthan et al., 2015; Wang H. W. et al., 2018). In recent years, many studies have shown that the saponins extracted from TCM has great anti-MIRI effects in vivo and in vitro; their mechanisms are diverse and mainly involve regulating energy metabolism and calcium homeostasis, and inhibiting oxidative stress and inflammation (Zhu et al., 2017; Wang et al., 2019). Saponins mainly include four-ring triterpene saponins and five-ring triterpene saponins. Among the tetracyclic triterpene type saponins, dammarane-type saponins have been studied in-depth, while among the pentacyclic triterpene-type saponins oleanane-type saponins are most widely distributed and studied (Leo et al., 2007; Hu et al., 2010; Shin et al., 2015; Zebiri et al., 2016). Each saponin also has its unique protection mechanism for MIRI due to its structural specificity.

In this review, we discuss the classic mechanisms of MIRI and a few emerging regulatory mechanisms (Figure 1). Based on the significant anti-MIRI effect of saponins, we classified and summarized the saponins with cardioprotective effects and analyzed their cardioprotective mechanisms. This review aims to provide potential treatment strategies and drug candidates for MIRI.

\section{MECHANISMS OF MYOCARDIAL ISCHEMIA-REPERFUSION INJURY Oxidative Stress and Myocardial Ischemia-Reperfusion Injury}

MIRI is accompanied by an excess of oxygen free radicals, and reactive oxygen species (ROS) are the main driving forces for reperfusion injury (Zhou et al., 2015). ROS and cellular redox states regulate many critical cellular activities. In presence of sufficient oxygen supply, ROS and endogenous antioxidants maintain balance to protect essential activities in the cell (Cadenas, 2018). MIRI damages the cellular antioxidant system and promotes oxidative damage. After reperfusion, the generation of excessive ROS, notably hydroxyl radicals, may cause the oxidation of proteins, lipids and nucleic acids (Dongo et al., 2011). This further leads to changes in protein function, membrane damage, gene mutations, and metabolic disorders, which generates oxidative stress. Superoxide anion $\left(\mathrm{O}^{2-}\right)$, hydroxyl radical $\left(\mathrm{OH}^{-}\right)$, and hydrogen peroxide $\left(\mathrm{H}_{2} \mathrm{O}_{2}\right)$, which are the culprits responsible for inducing oxidative stress in the vascular wall, are mainly produced through xanthine oxidase, NADPH oxidase, endothelial nitric oxide synthase, and other enzyme systems (Zhou et al., 2015). In other words, a close connection exists between endothelial cells and ROS injury. The enhancement of endogenous antioxidant activity and the intervention of exogenous antioxidants can effectively inhibit oxidative stress and reduce damage to cells (Matsushima et al., 2014; Zhao D. et al., 2017). Therefore, researchers have screened several natural compounds with antioxidant activity, such as araloside $\mathrm{C}$, dioscin, etlatoside $\mathrm{C}$, ginsenoside $\mathrm{Rb} 3$, and ginsenoside Rg3 (Xia et al., 2011; Wang M. et al., 2015), which are expected to protect the heart by inhibiting oxidative stress.

\section{Inflammatory Response and Myocardial Ischemia-Reperfusion Injury}

The inflammatory response activates during myocardial ischemia and is significantly aggravated during reperfusion (VintenJohansen et al., 2007). The adhesion and infiltration of neutrophils are the main pathological changes of coronary arteries after MIRI. After MIRI, the metabolism of arachidonic acid on the myocardial cell membrane increases, which leading the production of large amounts of leukotrienes, prostaglandins, and thromboxane A2 (Boag et al., 2017). And then the expression of special adhesion molecules on the surface of microvascular endothelial cells or leukocytes increases, which promotes the chemotaxis, adhesion and aggregation of neutrophils, increases the blood flow resistance of microvascular, and even causes noreflow phenomenon, aggravating myocardial ischemic damage (Arslan et al., 2008). Neutrophils adhere to the endothelial cells of the blood vessel wall under the guidance of adhesion molecules and then migrate to the myocardial tissue (Moos and Funk, 2008). During MIRI, the levels of inflammatory factors, including tumor necrosis factor- $\alpha$ (TNF- $\alpha$ ) and IL-1, significantly increase in the myocardial tissue causing myocardial damage. Antiinflammatory factors and pro-inflammatory factors co-exist 


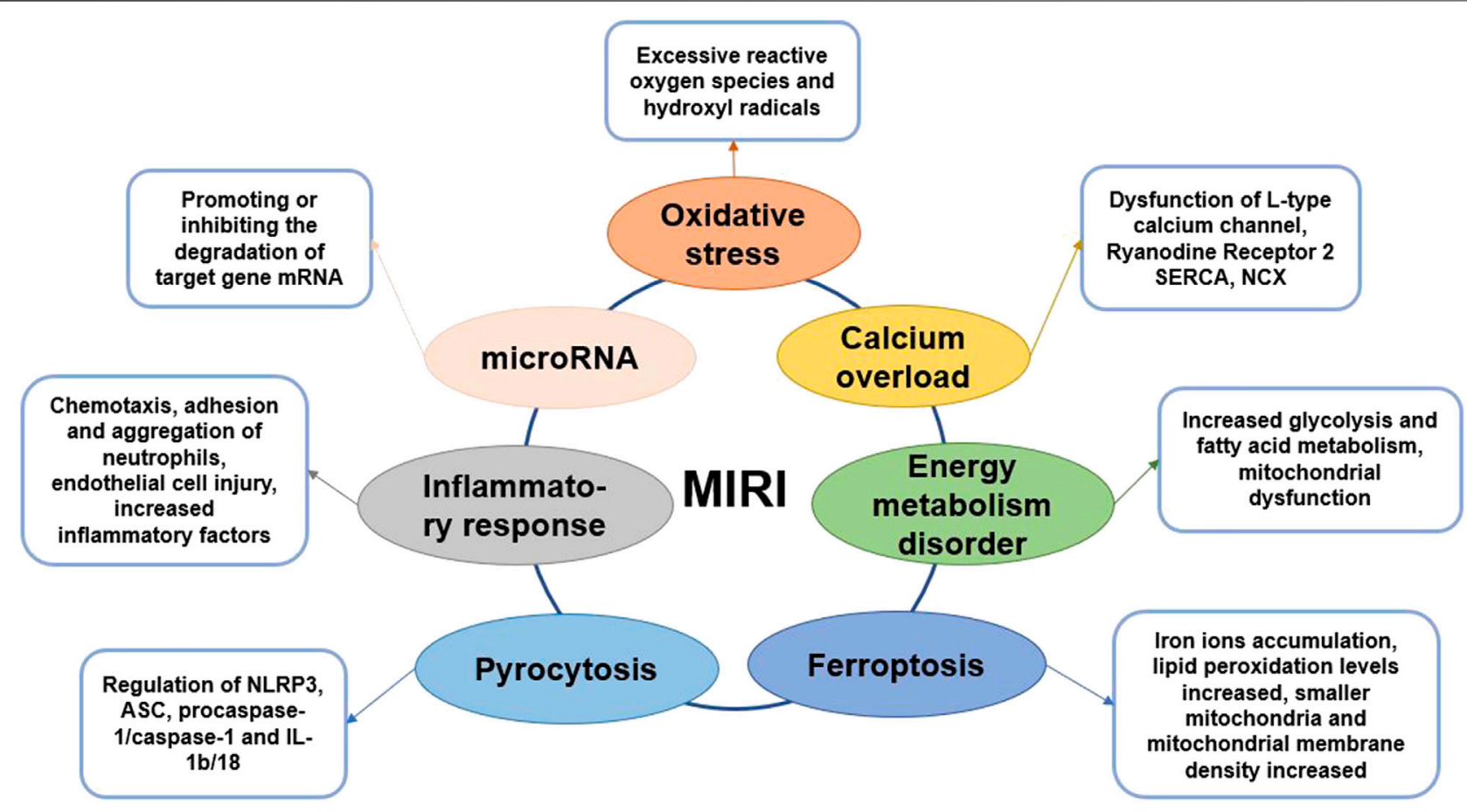

FIGURE 1 | Graphical summary of MIRI mechanism.

during MIRI, and generally, the pro-inflammatory factors are more dominant (Singhal et al., 2010).

Endothelial cells are closely related to inflammation, and endothelial dysfunction and microcirculation injury are important bases of MIRI. Studies have found that endothelial cells are more vulnerable to damage than cardiomyocytes during reperfusion, whereas cardiomyocytes are more vulnerable to damage during the ischemic phase (Singhal et al., 2010; Schanze et al., 2019). Therefore, coronary endothelial cells are critical mediators of myocardial dysfunction post MIRI. Autophagy of endothelial cells would cause structural and functional damage that hinders the blood flow to increase MIRI (Raivio et al., 2009; Russo et al., 2017). The mechanism of endothelial cells involved in MIRI may be related to the AMPK/mTOR and nuclear factor $\kappa \mathrm{B}$ (NF- $\kappa \mathrm{B})-\mathrm{p} 65-\mathrm{Beclin} 1$ pathways (Moos and Funk, 2008; Singhal et al., 2010). The role of NOD-like receptors (NLRs) with a pyrin domain 3 (NLRP3) inflammasome in MIRI is a current hot topic. NLRP3 can be combined with caspase- 1 and ASC to form the NLRP3 inflammasome, which requires NF- $\kappa B$ activation (Wang Y. et al., 2015; Li et al., 2017). Recent research on the role of NODlike receptor (NLR) with a pyrin domain 3 (NLRP3) inflammasome in MIRI is a hot topic. NLRP3 can be combined with caspase-1 and ASC to form the NLRP3 inflammasome, which requires NF- $\mathrm{kB}$ activation (Sandanger et al., 2016). NLRP3 inflammatory bodies promote the increase in IL-1 $\beta$ levels, triggering downstream inflammatory responses, including leukocyte recruitment and activation. Studies have shown that during the MIRI process, the activation of NLRP3 inflammatory bodies has cardioprotective effects (Vinten-Johansen et al., 2007; Sandanger et al., 2016). Some natural saponins, such as celastrol, ginsenoside Rb1, and ginsenoside $\mathrm{Rb} 3$, can reduce MIRI by inhibiting inflammation and restoring endothelial cell function (Wang Y. et al., 2015; Li et al., 2017).

\section{Calcium Overload and Myocardial Ischemia-Reperfusion Injury}

As the second messenger in the cell, $\mathrm{Ca}^{2+}$ can maintain cardiomyocyte function, proliferation, division, energy metabolism and other important processes (Verkhratsky and Parpura, 2014). During myocardial ischemia, ATP production decreases, resulting in decreased sarco-endoplasmic reticulum $\mathrm{Ca}^{2+}$ ATPase (SERCA) activity (Zhu et al., 2017). Thus, intracellular calcium transport is impaired, causing calcium overload. On reperfusion, ROS damage the cell membrane, leading to extracellular $\mathrm{Ca}^{2+}$ influx; NCX transports $\mathrm{Ca}^{2+}$ into the cells and discharges a large amount of $\mathrm{Na}^{+}$in the cell, exacerbating calcium overload (Ohtsuka et al., 2004). Intracellular $\mathrm{Ca}^{2+}$ regulates the contractile and diastolic function of cardiomyocytes and plays an essential role in excitation-contraction coupling (MacLennan and Kranias, 2003). The action potential triggers a small amount of $\mathrm{Ca}^{2+}$ to enter the cell through L-type calcium channels (LTCC), and a large amount of $\mathrm{Ca}^{2+}$ is released from the sarcoplasmic reticulum (SR) through ryanodine receptor 2 (RyR2). Then, calcium and troponin C combine to cause myocardial cell contraction (Grueter et al., 2007). SERCA can retake the intracellular $\mathrm{Ca}^{2+}$ to the SR, while NCX in the cell membrane can export $\mathrm{Ca}^{2+}$ from 
the cells, leading to relaxation of the cardiomyocytes (Fang et al., 2016). Therefore, the intracellular calcium level affects the excitability degree and relaxation rate of cardiomyocytes. The occurrence of calcium overload is bound to have a non-negligible effect on the contraction and relaxation of cardiomyocytes ( $\mathrm{Li}$ et al., 2013). Calcium overload is closely related to oxidative stress, and inflammatory response and these factors together promote MIRI process (Verkhratsky and Parpura, 2014). Therefore, inhibiting calcium overload is an effective method to reduce heart damage during MIRI. Some natural ingredients, such as ginsenoside $\mathrm{Re}$, ginsenoside $\mathrm{Rb}$, Elatoside $\mathrm{C}$ and Araloside C, can promote the restoration of calcium homeostasis and thus play a cardioprotective role (Wang et al., 2014; Wang M. et al., 2015).

\section{Energy Metabolism Disorder and Myocardial Ischemia-Reperfusion Injury}

In the early stage of myocardial ischemia, because the oxygenated hemoglobin in the ischemic tissue is consumed, the energy metabolism changes from aerobic oxidation of mitochondria to glycolysis (Cui et al., 2017; Alegre et al., 2020). So, ATP produced by glycolysis becomes dominating source of energy to the maintenance of myocardial cell survival. The enhancement of glycolysis induces the intracellular lactate increase, intracellular $\mathrm{pH}$ drops, which leading the calcium overload process is aggravated. In addition, the level of fatty acid oxidation and metabolism after MIRI significantly exceeds the level before ischemia, which slows the recovery of heart function (Li et al., 2018; Tian et al., 2019). The main reason is that fatty acid $\beta$ oxidation accelerates and ATP production increases, but oxygen consumption also increases (Lesnefsky et al., 2017).

To improve myocardial metabolism during MIRI, it is mainly to promote glucose metabolism and inhibit fatty acid metabolism. Optimizing energy metabolism is only a cytoprotective measure, and the therapeutic effect is limited. The treatment purpose of improving energy metabolism is to prolong the process of ischemic myocardial necrosis, buy precious time for myocardial revascularization therapy, and promote the recovery of heart function (Paradies et al., 2018). Because metabolic drugs have no obvious hemodynamic effects, it is recommended to use them in combination with $\beta$-receptor blockers. At present, there are many studies on trimetazidine and niacin, but the research progress is relatively slow due to some side effects (Wu et al., 2018). The saponins in natural products are safer to be used as medicines, and have the advantage of multiple targets. It is worth carefully exploring the effective ingredients of anti-MIRI. Studies have shown that ginsenosides including total ginsenosides, ginsenoside $\mathrm{Rg} 1$, ginsenoside $\mathrm{Rb} 1$ have a significant effect on energy metabolism (Cui et al., 2017; Li et al., 2018).

Mitochondria are the main organelles that produce ATP. Cardiomyocytes need to consume large amounts of ATP to maintain normal function. Oxygen is required for mitochondrial energy production (Alam et al., 2015). But during MIRI, the levels of oxygen reduce but those of ROS increase, which result in reduced ATP synthesis and mitochondrial permeability transition pores (MPTP) opening (Paradies et al., 2018). Therefore, MIRI causes energy metabolism disorders, and MPTP opening further promotes cardiomyocyte apoptosis and necrosis (Ong et al., 2015). In the meantime, pathways, including glycogen synthesis kinase $3 \beta$ (GSK-3 $\beta$ ) pathway, protein kinase C (PKC) pathway, signal transducer and activator of transcription 3 (STAT3) pathway and apoptosis signaling pathway, are activated successively (Makhdoumi et al., 2016; Lesnefsky et al., 2017). These pathways further affect the function of mitochondria, either promoting or inhibiting cardiomyocyte apoptosis (Zheng et al., 2017). Saponins, such as Araloside C, astragaloside IV, dioscin, ginsenoside $\mathrm{Rb} 1$, ginsenoside $\mathrm{Rd}$, ginsenoside $\mathrm{Rg} 1$ and notoginsenoside $\mathrm{R} 1$, can reduce MIRI by regulating mitochondrial function (Wang et al., 2012; Li et al., 2018).

Mitochondrial autophagy is a process that selectively removes damaged mitochondria to reduce cell damage. During MIRI, PTEN induces mitochondrial autophagy through pathways such as putative kinase 1 (PINK1)/Parkin, BNIP3/NIX, and FUNDC1 signaling pathway (Ney, 2015). Moderate mitochondrial autophagy has a protective effect on the maintenance of mitochondrial membrane potential and the normal structure and function of cell membranes, thereby reducing MIRI. In contrast, mitochondrial dysfunction leads to impaired autophagy function, insufficient clearance, or excessive activation of mitochondrial autophagy, which can increase MIRI (Shirakabe et al., 2016; Tong and Sadoshima, 2016). Exploring mitochondrial autophagy and its regulatory mechanism during MIRI may help to understand the relationship between mitochondrial autophagy and MIRI, and provide new ideas for the clinical treatment of MIRI.

\section{microRNA and Myocardial Ischemia-Reperfusion Injury}

In recent years, the application of microRNA (miRNA) and long noncoding RNAs (lncRNA) in MIRI treatment has increasingly become a research focus. miRNA is an endogenous, singlestranded, non-coding, small regulatory RNA in a variety of eukaryotic cells (Diaz et al., 2017). Studies have shown that miR-1275, miR-133, miR-148a and miR-324 interfere with the process of MIRI by inhibiting myocardial cell apoptosis, reducing myocardial inflammation, and promoting angiogenesis (Dai et al., 2020; Jiang et al., 2020; Zong and Wang, 2020). lncRNA is a heterogeneous non-coding RNA that can directly regulate the transcription of target genes and the degradation of proteins (Ruan et al., 2019). IncRNA has the function of competing or cooperating with endogenous RNA, which can promote or inhibit the degradation of target gene mRNA by miRNA, thereby regulating the expression of target gene mRNA and its protein (Xiong et al., 2019). The main functions of lncRNA include regulating gene methylation, transcription activation, and binding to mRNA and miRNA to affect the translation process (Pei et al., 2020). At present, most researches focus on the mechanism of lncRNA regulating miRNA. But miRNA can also regulate lncRNA. IncRNA and miRNA mainly regulate and treat MIRI through mechanisms such as oxidative stress, 
inflammatory infiltration, mitochondrial dysfunction, autophagy, and apoptosis (Ruan et al., 2019; Pei et al., 2020). To clarify the complex and delicate regulatory network of lncRNA-miRNAmRNA is important for revealing the interaction between RNA molecules (Xiong et al., 2019). The role and interpretation of the complex molecular network regulation between its functions is of vital importance, providing new therapeutic targets for the treatment of MIRI.

\section{Pyrocytosis and Myocardial Ischemia-Reperfusion Injury}

Pyroptosis is a new form of programmed cell death that is accompanied by inflammatory reactions (Bergsbaken et al., 2009). It is characterized by morphological necrosis and apoptosis. However, its features are entirely different, for example, nuclear shrinkage, DNA breakage, and a large number of 1-2 nm-diameter holes on the cell membrane are observed (Jia et al., 2019). Pyroptosis mainly depends on caspase- 1 and is accompanied by an inflammatory cascade. During MIRI, ASC combines with procaspase- 1 to form a multi-protein complex that activates caspase1 , which in turn induces the activation of IL- $1 \beta$ and IL-18, recruits more inflammatory factors, and expands the inflammatory response (Toldo et al., 2018; Wang Z. et al., 2018). NLRP3 is also an important factor that initiates cell pyroptosis and mediates the production of IL- $1 \beta$ and IL-18. In the early stage of MIRI, NLRP3 inflammation is activated before apoptosis, indicating its participation in the pathological process of MIRI, and therefore it may be considered a marker of early MIRI (Allam et al., 2014; Qiu et al., 2017; Yumnamcha et al., 2019). Hence, understanding the specific role of NLRP3, ASC, procaspase-1/caspase-1, IL-1b/18, and other proteins related to the pyroptosis signaling pathway in MIRI is essential to develop targeted cell pyroptosis and provide new ideas for MIRI prevention in the future (Yang et al., 2018; Wu et al., 2019).

\section{Ferroptosis and Myocardial Ischemia-Reperfusion Injury}

Ferroptosis is a new form of cell death caused by MIRI (Baba et al., 2018). It is characterized by the generation of ROS through the reaction of ferritin, which causes the accumulation of lipid peroxides and manifests in iron ion accumulation, increased lipid peroxidation levels, smaller mitochondria, and increased mitochondrial membrane density (Xie et al., 2016; Fang et al., 2019). Due to its iron-dependent characteristics, ferroptosis is genetically and biochemically different from other forms of cell death. Inhibitors of apoptosis, pyroptosis, and autophagy cannot prevent the occurrence of ferroptosis, but iron-chelating agents can inhibit cell ferroptosis (Baba et al., 2018; Yumnamcha et al., 2019). Ferroptosis-induced ERS leads to apoptosis, which is closely related to MIRI; ferroptosis induces an unfolded protein response during ERS and subsequently activates the PERK-eIF2 $\alpha$-ATF4-CHOP signaling pathway, leading to apoptosis, which plays a vital role in the process of MIRI (Peng et al., 2020). Moreover, p53 upregulates apoptosis regulators and participates in the synergy between ferroptosis and apoptosis (Chen et al., 2019; Sumneang et al., 2020).
However, although ferroptosis is closely related to MIRI, its precise molecular mechanism and biological function are not yet fully elucidated. Research on its mechanism is expected to provide new insights for MIRI treatment.

\section{Interaction Among Myocardial Ischemia-Reperfusion Injury Mechanisms}

Due to ischemia and hypoxia of myocardial tissue, energy metabolism disorder is the initiation of MIRI (Lesnefsky et al., 2017). In addition, the ischemic and hypoxic environment creates a certain material basis for the formation of oxygen free radicals (Chen and Chow, 2005). With the massive formation of oxygen free radicals, it directly or indirectly leads to calcium overload in myocardial cells. Calcium overload can cause damage to mitochondrial structure and function under the joint participation of inflammatory (Verkhratsky and Parpura, 2014). Calcium overload and mitochondrial dysfunction are mutually causal, forming a vicious circle, and ultimately leading to irreversible damage to cardiomyocytes. During the MIRI, pyroptosis is accompanied by inflammation, and ferroptosis is related to apoptosis caused by ERS (Toldo et al., 2018; Li W. et al., 2020). In addition, miRNA can regulate the expression of genes related to oxidative stress, inflammation, energy metabolism disorder, apoptosis, and calcium overload. Therefore, the mechanism of MIRI involves multiple factors and multiple levels, and these factors are interrelated and synergistic, which together lead to serious myocardial tissue damage.

\section{SAPONINS IN THE TREATMENT OF MYOCARDIAL ISCHEMIA-REPERFUSION INJURY}

\section{Protective Mechanism of Saponins From Ginseng Against Myocardial Ischemia-Reperfusion Injury}

Ginsenosides are essential bioactive ingredients of Araliaceae plants, such as Panax ginseng C. A. Mey., Panax notoginseng (Burk.) F. H. Chen, and Panax quinquefolium L., as well as Cucurbitaceae plants such as Gynostemma pentaphyllum (Thunb) Makino (Hu et al., 2010; Shin et al., 2015). Panax ginseng C. A. Mey. and Panax notoginseng (Burk.) F. H. Chen are the two main plant sources of ginsenosides. Among them, authentic Panax ginseng C. A. Mey. is mainly distributed in Southwest China, East Asia and North America, and authentic Panax notoginseng (Burk.) F. H. Chen is mainly distributed in Southwest China. Although the proportion of ginsenosides in these Chinese herbal medicines varies, all of them are excellent TCMs for anti-tumor, anti-oxidation, anti-aging, anti-fatigue, regulating blood sugar balance, improving cardiovascular and cerebrovascular, and enhancing immunity (Chen et al., 2011; Wang et al., 2012). Xuesaitong, the main active ingredient of Panax notoginseng saponins, is currently used in the clinical treatment of cardiovascular and cerebrovascular diseases and activates blood circulation, alleviates blood stasis, and expands blood vessels ( $\mathrm{Li}$ et al., 2019). Studies show that Xuesaitong injection can reduce 
MIRI by promoting pyruvate dehydrogenase-mediated aerobic metabolism (Zhao X. et al., 2017). Ginseng total saponins can also enhance myocardial energy metabolism by regulating the tricarboxylic acid cycle pathway as well as reduce MIRI by inhibiting inflammation and oxidative damage (Wang et al., 2012). Panax notoginseng saponins were found to have a protective effect against rat MIRI and cardiomyocyte hypoxia-reoxygenation (HR) by regulating autophagy and apoptosis via the HIF-1 $\alpha /$ BNIP3 and PI3K/Akt pathways (Chen et al., 2011) (Table 1).

Ginsenosides, such as ginsenoside Rb1, ginsenoside Rg1, ginsenoside $\mathrm{Rb} 3$, ginsenoside $\mathrm{Rg} 3$, ginsenoside $\mathrm{Rd}$, and ginsenoside $\mathrm{Re}$, are mainly dammarane-type structures, with different types and positions of glycosides that result in unique physicochemical and biological activities (Aravinthan et al., 2015; Liu X.-W. et al., 2019) (Figure 2). Ginsenoside Rb1, a common saponin in Panax ginseng C. A. Mey., Panax notoginseng (Burk.) F. H. Chen, and Panax quinquefolium L., has an excellent therap effect on MIRI in vivo and ex vivo, mainly by inhibiting apoptosis pathways and activating mTOR phosphorylation (Li C. Y. et al., 2020). Moreover, ginsenoside Rb1 as well as ginsenoside Rg1, improved heart function by improving energy metabolism via the RhoA signaling pathway, which is similar to the cardiac regulation by ginseng total saponins (Cui et al., 2017). Ginsenoside Rg1 also protected H9c2 cardiomyocytes by inhibiting apoptosis, or activating the PI3K/AKT/mTOR pathway (Deng et al., 2015; Li et al., 2018; Qin et al., 2018; Yuan et al., 2019). In addition, ginsenoside $\mathrm{Rd}$ restored mitochondrial damage and inhibited oxidative stress by activating the Akt/GSK-3 $\beta$ and Nrf2/HO-1 signaling pathways (Wang et al., 2013; He et al., 2014; Yu et al., 2016c). Notoginsenoside R1 reduced MIRI by preventing energy metabolism disorder and ERS, which was related to the ROCK and $\mathrm{NF}-\kappa \mathrm{B}$ signaling pathways.

In summary, total ginsenoside as well as ginsenoside monomer components can significantly reduce MIRI and HR damage. The specific regulatory mechanisms of ginsenosides mainly reduce energy metabolism disorders, inhibit oxidative stress and inflammatory response, and reduce cardiomyocyte apoptosis ( $\mathrm{Li}$ et al., 2016; Zhang et al., 2016). Notably, the regulation of energy metabolism by ginsenosides, mainly through the Akt/GSK-3 $\beta$ and RhoA/ROCK signaling and mitochondrial autophagy pathways, is particularly significant and coincides with the significance of ginseng's TCM guidance (Figure 3). Various ginsenosides can protect against MIRI through the regulation of different signaling pathways. The clinical efficacy of ginsenosides also encourages researchers to further explore the mechanism underlying the treatment of cardiovascular diseases, provide a theoretical basis for their clinical application, and expand ginseng indications.

\section{Protective Mechanism of Saponins From Aralia Against Myocardial Ischemia-Reperfusion Injury}

Aralia chinensis L. is an edible Araliaceae plant with medicinal value, including Aralia elata (Miq) Seem. and Aralia taibaiensis (Wang et al., 2014). Aralia elata (Miq) Seem. is mainly distribution in Northeast China, North Korea, Japan and Russia, and Aralia taibaiensis is distribution in Midwest China. It contains several triterpene saponins, flavonoids, coumarins, and alkaloids, of which saponins are its main active ingredient (Wang R. et al., 2018). Current research shows that Aralia saponins can regulate the cardiovascular system and possess anti-tumor and anti-inflammatory effects (Yan et al., 2015). The total saponin of Aralia elata constitute the main component of the Longya Guanxinkang capsule, which functions to nourish qi, promote blood circulation, reduce blood stasis, and relieve pain; it is suitable for treating coronary heart disease, angina pectoris with qi deficiency, and blood stasis syndrome (Wang R. et al., 2018). In addition, Aralia Xinmaitong capsules, developed with total saponins of Aralia elata as ingredients, have obtained drug clinical research approval for the treatment of angina pectoris caused by qi deficiency and blood stasis (Wang M. et al., 2015). Our team has previously proved that total saponins of Aralia elata (Miq) Seem. protects against MIRI by suppressing ERS-related apoptosis and calcium overload via the PKCe-dependent signaling pathway (Wang R. et al., 2018). Total saponins of A. taibaiensis also showed a protective effect against MIRI (in vivo) and $\mathrm{HR}$ (in vitro), and the protective mechanism was associated with AMPK pathway-related apoptosis (Yan et al., 2015).

After screening a large number of saponin components, three components with strong anti-MIRI activity were identified: elatoside $\mathrm{C}$, araloside $\mathrm{C}$, and calenduloside $\mathrm{E}$ (Table 2). The chemical structures of these saponins have oleanolic acid configurations (Figure 4). Calenduloside E contains fewer glycosidic bonds than elatoside $\mathrm{C}$ and araloside $\mathrm{C}$, which results in its marginal inferior solubility and different biological activities. Further, calenduloside $\mathrm{E}$ reportedly reduced $\mathrm{H}_{2} \mathrm{O}_{2}$-induced $\mathrm{H} 9 \mathrm{c} 2$ cardiomyocyte injury by inhibiting oxidative stress, apoptosis, and calcium overload (Tian et al., 2017). Elatoside $\mathrm{C}$ protected against rat global MIRI by attenuating oxidative stress and calcium overload via PI3K/Akt and JAK2/STAT3 signaling pathway activation and MPTP inhibition (Wang M. et al., 2015). Araloside $\mathrm{C}$ reduced oxidative stress, ERS, and calcium overload by regulating Hsp90, and improved mitochondrial function and AMPK activation, which were dedicated to alleviating rat global MIRI and H9c2 cardiomyocyte HR damage (Wang et al., 2017; Du et al., 2018; Wang et al., 2019).

In short, Aralia saponins have an excellent effect on the treatment of coronary heart disease and angina pectoris (Wang R. et al., 2018). Current studies have shown that the cardioprotective effect of Aralia saponins is mainly through inhibition of calcium overload, oxidative stress and ER stress-related apoptosis. Aralia saponins showed a significant role in maintaining calcium homeostasis, primarily by activating HSP90, PKCe and JAK2/ STAT3 signaling pathways, inhibiting MPTP opening (Wang et al., 2014; Wang M. et al., 2015; Du et al., 2018) (Figure 3). However, the current research on MIRI protective mechanism of Aralia saponins is not deep enough, and some data on animals in vivo experiments and clinical studies are insufficient.

\section{Protective Mechanism of Other Saponins Against Myocardial Ischemia-Reperfusion Injury}

In addition to ginsenosides and aralia saponins, other saponins also possess anti-MIRI activity (Table 3). Since each saponin has a different chemical structure, its characteristic cardiac protection mechanism also differs. Radix Astragali is a known TCM for 
TABLE 1 | Anti-MIRI effects of saponins from ginseng.

\begin{tabular}{|c|c|c|c|c|c|}
\hline Compound & $\begin{array}{c}\text { Major plant } \\
\text { source }\end{array}$ & $\begin{array}{l}\text { Geographical } \\
\text { distribution } \\
\text { of plants }\end{array}$ & $\begin{array}{c}\text { Dose/ } \\
\text { concentration }\end{array}$ & Models & Mechanism \\
\hline
\end{tabular}

Ginseng total Panax ginseng C. A. Mey Southwest China, East saponins Asia and North America

$50 \mathrm{mg} / \mathrm{L}$ for $60 \mathrm{~min}$

Panax notoginseng Panax notoginseng Southwest China saponins (Burk.) F. H. Chen

Gypenoside

Panax notoginseng

Southwest China; East (Burk.) F. H. Chen; Gynostemma pentaphyllum (Thunb.) Mak Asia and Southeast Asia

Ginsenoside Rb1 Panax ginseng C. A. Southwest China, East Mey.; Panax notoginseng Asia and North America; (Burk.) F. H. Chen Southwest China

Ginsenoside Rb3 Panax ginseng C. A. Southwest China, East Mey.; Panax notoginseng Asia and North America; (Burk.) F. H. Chen Southwest China

Ginsenoside Rd Panax ginseng C. A. Southwest China, East Mey.; Panax notoginseng Asia and North America; (Burk.) F. H. Chen Southwest China

Ginsenoside Re Panax ginseng C. A. Southwest China, East Mey.; Panax notoginseng Asia and North America; (Burk.) F. H. Chen Southwest China

Ginsenoside Rg1 Panax ginseng C. A. Southwest China, East Mey.; Panax notoginseng Asia and North America; (Burk.) F. H. Chen Southwest China

Ginsenoside Rg3 $\quad \begin{array}{ll}\text { Panax ginseng C. A. } & \text { Southwest China, East } \\ \text { Mey.; Panax notoginseng } & \text { Asia and North America; }\end{array}$ (Burk.) F. H. Chen Southwest China

Notoginsenoside R1
Panax notoginseng

(Burk.) F. H. Chen
Southwest China

Southwest China (Aravinthan et al., 2015)

100, 200 mg/kg, i.g. Guinea pig MIRI model (in vivo) Rat global MIRI model (ex vivo) (Wang et al., 2012)

$200,500 \mu \mathrm{g} / \mathrm{ml}$

Neonatal rat MIRI model (in vitro) (Wang et al., 2019)

30, $60 \mathrm{mg} / \mathrm{kg}$, i.p. Rat MIRI model (in vivo) (Liu X.W. et al., 2019)

30, 60 mg/kg, i.g.; Rat MIRI model (in vivo); H9c2 $0.05,0.25$, $2.25 \mathrm{mg} / \mathrm{ml}$ 50, 100, $200 \mathrm{mg} / \mathrm{kg}$, i.g.; 5 10, $20 \mu \mathrm{M}$ cardiomyocytes HR model (in vitro) (Chen et al., 2011) Rat MIRI model (in vivo); H9c2 (in vitro) (Yu et al., 2016a; Yu et al., 2016b)

100 mg/kg, i.g. (in Rat MIRI model (in vivo); H9c2 vivo); $10,20 \mu \mathrm{M}$ cardiomyocytes $\mathrm{HR}$ model (in vitro)

$40 \mathrm{mg} / \mathrm{kg}$, i.g. (in vitro) (Chang et al., 2020)
Rat MIRI model (in vivo) (Xia et al., 2011; Li et al., 2016)
Anti-oxidative and anti-inflammatory properties by reducing inflammatory cytokines and NF-kB

Modulating TCA cycle protein expression to enhance cardiac energy metabolism; reducing oxidative stress Inhibiting oxidative stress via MiR$30 c-5 p$

Regulating the HIF-1a/BNIP3 pathway of autophagy

Inhibiting apoptosis by activating PI3K/ Akt pathway

Inhibiting ER-stress and apoptosis via CHOP pathway and PI3K/Akt pathway; inhibiting NF-kB p65 activation via MAPK signaling pathway Suppressing miR-143-3p level via the activation of AMPK/Foxo1 signaling pathway

Enhancing eNOS expression and NO content and inhibiting p38-MAPK signaling pathway

20, 40, $80 \mathrm{mg} / \mathrm{kg}$, Rat global MIRI model (ex vivo); Activating mTOR signal pathway i.g.; 1, 5, 10, $20 \mu \mathrm{M}$ rat MIRI model (in vivo) (Li C. Y.

$\begin{array}{ll}2.5,5, & \text { et al., 2020) } \\ \text { Rat MIRI model (in vivo) (Cui }\end{array}$

$7.5 \mathrm{mg} / \mathrm{kg}$, i.g

$2,5 \mu \mathrm{M}$

et al., 2017)

Regulating energy metabolism by RhoA signaling pathway

H9c2 cardiomyocytes HR model Inhibiting JNK-mediated NF-kB (in vitro) (Ma et al., 2014) activation

5, 10, 20 mg/kg, i.g. Rat MIRI model (in vivo) (Shi et al., Anti-oxidantive, anti-apoptotic and 2011; Liu et al., 2013) anti-inflammatory activity; improving microcirculatory

$50 \mathrm{mg} / \mathrm{kg}$, i.p. Rat MIRI model (in vivo) (Zeng et Activating Nrf2/HO-1 signaling al., 2015) pathway

$50 \mathrm{mg} / \mathrm{kg}$, i.p.; $10 \mu \mathrm{M}$ Rat MIRI model (in vivo); neonatal Activating Akt/GSK-3 $\beta$ signaling

$0.3,1,3,10,20 \mu \mathrm{M}$ Guinea-pig cardiomyocyte

30, $100 \mu \mathrm{M}$

$5 \mathrm{mg} / \mathrm{kg} / \mathrm{h}$, $30 \mathrm{~min}$, i.v

$100 \mu \mathrm{M}$

$5,20 \mathrm{mg} / \mathrm{kg}$, i.g.

$60 \mathrm{mg} / \mathrm{kg}$, i.p.;

$10 \mathrm{mM}$

$5,10,20 \mu \mathrm{M}$

$5 \mathrm{mg} / \mathrm{kg}$, i.g.; 10 $100 \mathrm{nM}$

20, 40, $60 \mathrm{mg} / \mathrm{kg}$, i.g. rat myocardial cells HR model (in vitro) (Wang et al., 2013) electrophysiology (in vivo) (Bai et al., 2004) Rat MIRI model (in vivo) (Lim et al., 2013) Rat MIRI model (in vivo) (Li et al., 2018, Yuan et al. 2019)

pathway and inhibiting mitochondriadependent apoptotic pathway NO-dependent modulation of the delayed rectifier $\mathrm{K}^{+}$current and the L-type $\mathrm{Ca}^{2+}$ current

Ameliorating the electrocardiographic abnormality and inhibiting TNF- $a$ level Inhibiting apoptosis and modulating energy metabolism through binding to RhoA; activating HIF-1 a-ERK signaling pathways

H9c2 cardiomyocytes HR model Inhibiting autophagosomal formation (in vitro) (ZL et al., 2012; Qin et al, and apoptosis; activating the PI3K/ 2018) AKT/mTOR pathways

Rat MIRI model (in vivo) (Zhang et al., 2016)

Rat MIRI model (in vivo); neonatal rat myocardial cells HR model (in vitro) (Wang Y. et al., 2015) Rat global MIRI injury model (ex vivo); H9c2 cardiomyocytes HR model (in vitro) (Yu et al., 2016c) Rat MIRI model (in vivo); H9c2 cardiomyocytes HR model (in vitro) (He et al., 2014) Rat MIRI model (in vivo)
Anti-apoptosis and anti-inflammation properties

Regulating Akt/eNOS signaling pathway and $\mathrm{Bcl}-2 / \mathrm{Bax}$ signaling pathway

Inhibiting oxidative stress and ERS

Preventing energy metabolism disorder via inhibiting ROCK

Regulating vitamin D3 upregulated protein $1 / \mathrm{NF}-\kappa \mathrm{B}$ signaling pathway 

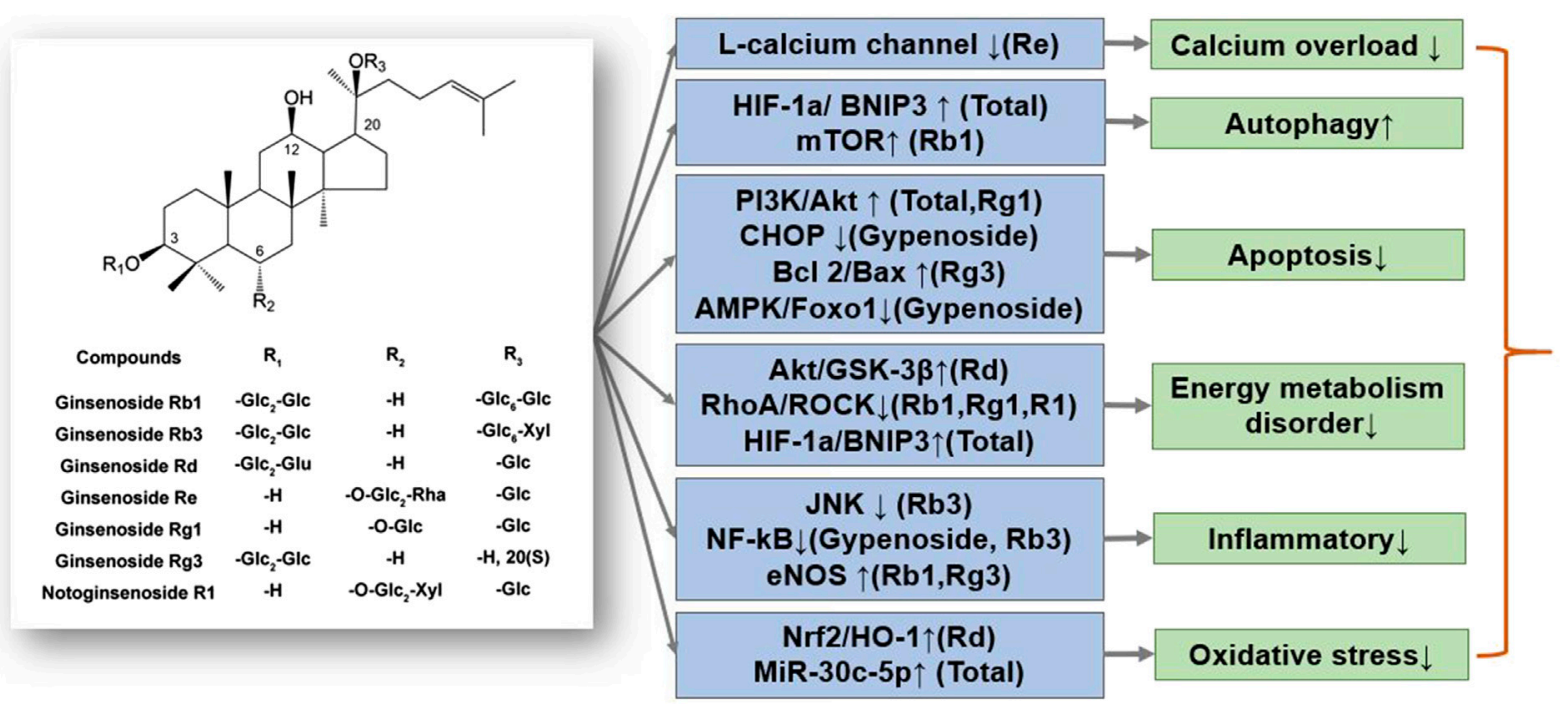

FIGURE 2 | A schematic representation of mechanisms of saponins from Ginseng exerted cardioprotective effects in MIRI. Glc, glucose; Rha, rhamnose; Xyl, xylopyranose. $\uparrow$ means activate relevant pathways. \means suppress relevant pathways.

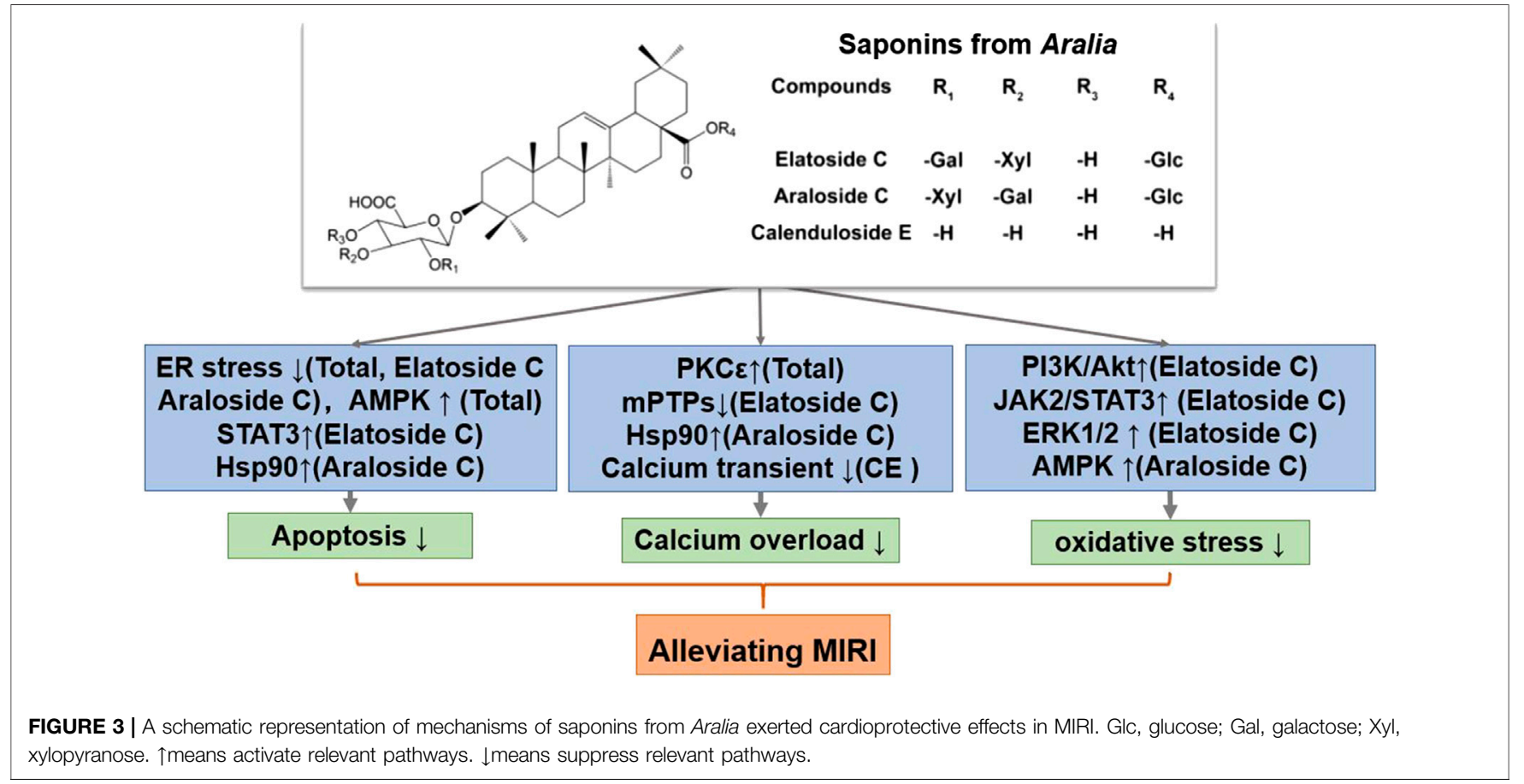

nourishing qi and is widely used in prescriptions and health products. Pharmacological studies have confirmed that Radix Astragali has a significant effect on the immune as well as cardiovascular systems (Tu et al., 2013). Huangqi Tongbi decoction, an ancient prescription for treating coronary heart disease that has Radix astragali as the main active ingredient, has been shown to significantly improve MIRI in rats; its cardiac protection mechanism involves inflammation suppression via the
HMGB1/TLR/NF- $\kappa B$ pathway (Liu K. et al., 2019). In addition, several studies on the anti-MIRI effect of astragaloside IV have identified it as the main component of Astragalus responsible for exerting cardiac protection. The mechanism of cardioprotection by astragaloside IV mainly focuses on the improvement of energy metabolism disorders by recovering mitochondrial respiration, preventing MPTP opening, and decreasing cytochrome $\mathrm{C}$ release (Xu et al., 2008; Han et al., 2011; Tu et al., 2013). The structure of 
TABLE 2 | Anti-MIRI effects of saponins from Aralia.

\begin{tabular}{|c|c|c|c|c|c|}
\hline Compound & $\begin{array}{l}\text { Major plant } \\
\text { source }\end{array}$ & $\begin{array}{l}\text { Geographical } \\
\text { distribution } \\
\text { of plants }\end{array}$ & $\begin{array}{l}\text { Dose/ } \\
\text { Concentration }\end{array}$ & Models & Mechanism \\
\hline \multirow[t]{2}{*}{$\begin{array}{l}\text { Total saponins of } \\
\text { Aralia elata (Miq) } \\
\text { Seem }\end{array}$} & $\begin{array}{l}\text { Aralia elata } \\
\text { (Miq) Seem }\end{array}$ & $\begin{array}{l}\text { Northeast China, North } \\
\text { Korea, Japan, Russia }\end{array}$ & $\begin{array}{c}25,50 \\
100 \mathrm{mg} / \mathrm{kg}, \text { i.g. }\end{array}$ & $\begin{array}{l}\text { Rat MIRI model (in vivo) (Wang R. et al., } \\
\text { 2018) }\end{array}$ & $\begin{array}{l}\text { Alleviating calcium homeostasis } \\
\text { imbalance and endoplasmic reticulum } \\
\text { stress-related apoptosis }\end{array}$ \\
\hline & & & $\begin{array}{l}30,60 \mathrm{mg} / \mathrm{kg} ; 1.25 \\
2.5 \text { and } 5 \mathrm{mg} / \mathrm{ml}\end{array}$ & $\begin{array}{l}\text { Dog hemodynamic indexes (in vivo), } \mathrm{Ca}^{2+} \\
\text { transients and sarcomere shortening } \\
\text { detection (in vitro) (Wang et al., 2014) }\end{array}$ & $\begin{array}{l}\text { Positive inotropic effect by maintenance } \\
\text { of calcium homeostasis and increase of } \\
\text { PKC } \varepsilon \text {-dependent signaling pathway }\end{array}$ \\
\hline $\begin{array}{l}\text { Total saponins of } \\
\text { Aralia taibaiensis }\end{array}$ & $\begin{array}{l}\text { Aralia } \\
\text { taibaiensis }\end{array}$ & Midwest China & $\begin{array}{l}\text { 60, } 120,240 \mathrm{mg} / \mathrm{kg} \\
\text { i.g.; } 25,50 \mu \mathrm{g} / \mathrm{ml}\end{array}$ & $\begin{array}{l}\text { Rat MIRI model (in vivo); H9c2 } \\
\text { cardiomyocytes HR model (in vitro) (Yan } \\
\text { et al., 2015) }\end{array}$ & $\begin{array}{l}\text { Suppressing apoptosis via the AMPK } \\
\text { pathway }\end{array}$ \\
\hline \multirow[t]{2}{*}{ Elatoside C } & $\begin{array}{l}\text { Aralia elata } \\
\text { (Miq) Seem }\end{array}$ & $\begin{array}{l}\text { Northeast China, North } \\
\text { Korea, Japan, Russia }\end{array}$ & $2,10,50 \mathrm{nM}$ & $\begin{array}{l}\text { Rat global MIRI injury model (ex vivo) } \\
\text { (Wang M. et al., 2015) }\end{array}$ & $\begin{array}{l}\text { Attenuating oxidative stress and calcium } \\
\text { overload through the activation PI3K/Akt } \\
\text { and ERK } 1 / 2 \text { and JAK2/STAT3 signaling } \\
\text { pathway and inhibiting the opening of } \\
\text { mPTPs }\end{array}$ \\
\hline & & & $12.5,25,50 \mu \mathrm{M}$ & $\begin{array}{l}\text { H9c2 cardiomyocytes HR model (in vitro) } \\
\text { (Wang et al., 2014) }\end{array}$ & $\begin{array}{l}\text { Activating STAT3 signaling pathway and } \\
\text { reducing ER stress-associated } \\
\text { apoptosis }\end{array}$ \\
\hline \multirow[t]{2}{*}{ Araloside C } & $\begin{array}{l}\text { Aralia elata } \\
\text { (Miq) Seem }\end{array}$ & $\begin{array}{l}\text { Northeast China, North } \\
\text { Korea, Japan, Russia }\end{array}$ & $\begin{array}{l}0.5,1,2.5 \mu \mathrm{M} ; 3.125 \\
6.25,12.5,25 \mu \mathrm{M}\end{array}$ & $\begin{array}{l}\text { Rat global MIRI injury model (ex vivo); } \\
\text { H9c2 cardiomyocytes HR model (in vitro) } \\
\text { (Wang et al., 2017; Du et al., 2018) }\end{array}$ & $\begin{array}{l}\text { Reducing oxidative stress, ER stress } \\
\text { and calcium overload by regulating } \\
\text { Hsp90 }\end{array}$ \\
\hline & & & $6.25,12.5,25 \mu \mathrm{M}$ & $\begin{array}{l}\mathrm{H}_{2} \mathrm{O}_{2} \text {-induced } \mathrm{H} 9 \mathrm{c} 2 \text { cardiomyocyte injury } \\
\text { (in vitro) (Wang et al., 2019) }\end{array}$ & $\begin{array}{l}\text { Reducing oxidative stress by regulating } \\
\text { mitochondrial function and AMPK } \\
\text { activation }\end{array}$ \\
\hline Calenduloside $\mathrm{E}$ & $\begin{array}{l}\text { Aralia elata } \\
\text { (Miq) Seem }\end{array}$ & $\begin{array}{l}\text { Northeast China, North } \\
\text { Korea, Japan, Russia }\end{array}$ & $0.02,0.1,0.5 \mu \mathrm{g} / \mathrm{ml}$ & $\begin{array}{l}\mathrm{H}_{2} \mathrm{O}_{2} \text {-induced } \mathrm{H} 9 \mathrm{c} 2 \text { cardiomyocyte injury } \\
\text { (in vitro) (Tian et al., 2017) }\end{array}$ & $\begin{array}{l}\text { Inhibiting oxidative stress, apoptosis } \\
\text { and calcium overload }\end{array}$ \\
\hline
\end{tabular}

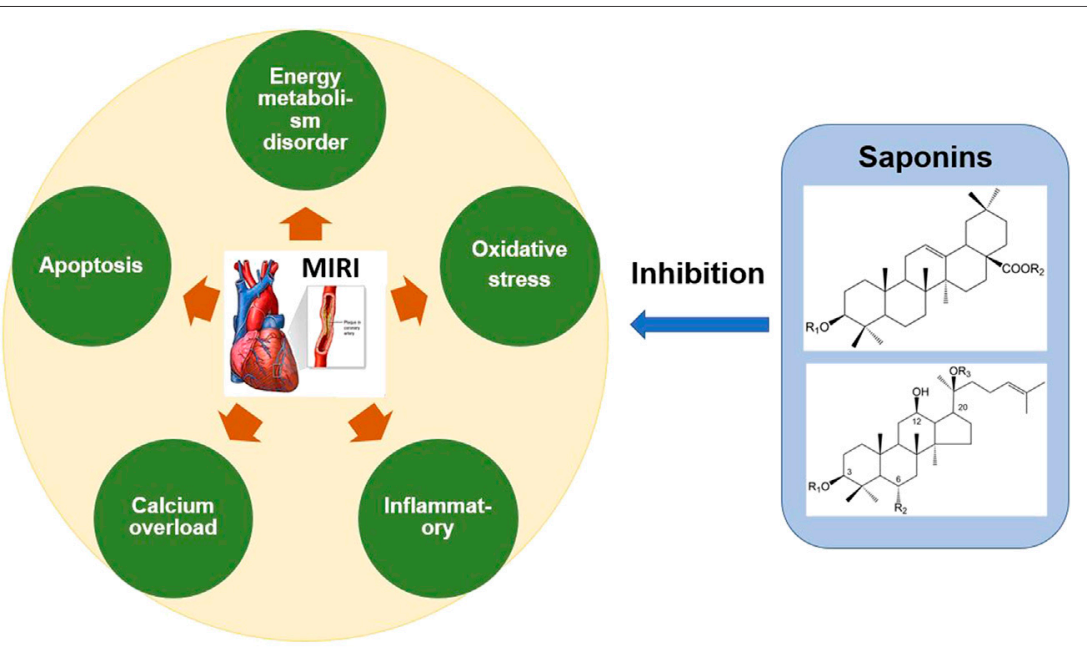

FIGURE 4 | Mechanism of anti-MIRI of saponins in Chinese Herbal Medicine. The saponins in Panax ginseng, Panax notoginseng, Aralia, Astragalus and other Chinese herbal medicine can significantly alleviate MIRI. These saponins inhibit oxidative stress, energy metabolism disorder, calcium overload, inflammation and apoptosis, and thus exert the cardioprotective effect.

astragaloside IV is similar to that of dammarane-type ginsenosides, and both possess the same cardiac protection mechanism, which supports the idea of structure determines function.

Dioscin is a phytoestrogen that exhibits anti-MIRI activity. Diosgenin exerts cardioprotective effects by inhibiting inflammation and oxidative stress by activating mitochondrial $\mathrm{K}_{\mathrm{ATP}}$ channels and regulating $\mathrm{p} 38$-MAPK/JNK pathways (Badalzadeh et al., 2014; Badalzadeh et al., 2015; Wang H. W. et al., 2018). Estrogen and its receptors are both critical targets in the MIRI mechanism; therefore, dioscin can also be used as a drug candidate for the treatment of MIRI, and its cardioprotective 
TABLE 3 | Anti-MIRI effects of other saponins.

\begin{tabular}{|c|c|c|c|c|c|}
\hline Compound & $\begin{array}{l}\text { Major plant } \\
\text { source }\end{array}$ & $\begin{array}{l}\text { Geographical } \\
\text { distribution } \\
\text { of plants }\end{array}$ & Dose/concentration & Models & Mechanism \\
\hline \multirow[t]{5}{*}{ Astragaloside IV } & $\begin{array}{l}\text { Astragalus } \\
\text { membranaceus }\end{array}$ & Northern China & 1,10 mg/kg, i.g. & $\begin{array}{l}\text { Rat MIRI model (in vivo) (Tu et al., } \\
\text { 2013) }\end{array}$ & Regulating energy metabolism \\
\hline & (Fisch.) Bge. & & $3,10,30 \mu \mathrm{M}$ & $\begin{array}{l}\text { Neonatal rat myocardial cells HR } \\
\text { model (in vitro) (Xu et al., 2008) }\end{array}$ & $\begin{array}{l}\text { Improving intracellular calcium } \\
\text { handling via regulating SERCA }\end{array}$ \\
\hline & & & $\begin{array}{c}5 \mathrm{mg} / \mathrm{kg} \text {, i.g.; } 10,20 \\
40 \text {, or } 80 \mu \mathrm{M}\end{array}$ & $\begin{array}{l}\text { Rat global MIRI injury model (ex } \\
\text { vivo); H9c2 cardiomyocytes HR } \\
\text { model (in vitro) (Luo et al., 2019) }\end{array}$ & $\begin{array}{l}\text { Recovering mitochondrial } \\
\text { respiration, preventing mPTP } \\
\text { opening, decreasing cytochrome } \\
\text { C release and preventing } \\
\text { apoptosis; regulating KATP } \\
\text { channel }\end{array}$ \\
\hline & & & $0.1,1,10,100 \mu \mathrm{M}$ & $\begin{array}{l}\text { H9c2 cardiomyocytes HR model } \\
\text { (in vitro) (Yang et al., 2018) }\end{array}$ & $\begin{array}{l}\text { Regulating } \mathrm{PI} 3 \mathrm{~K} / \mathrm{Akt} / \mathrm{HO}-1 \\
\text { signaling pathway }\end{array}$ \\
\hline & & & 80 mg/kg, i.g.; $60 \mu \mathrm{M}$ & $\begin{array}{l}\text { Rat MIRI model (in vivo); H9c2 } \\
\text { cardiomyocytes HR model (in vitro) } \\
\text { (Yin et al., 2019) }\end{array}$ & $\begin{array}{l}\text { Inhibiting CaSR/ERK1/2 and the } \\
\text { related apoptotic signaling } \\
\text { pathways; regulating energy } \\
\text { metabolism }\end{array}$ \\
\hline \multirow[t]{2}{*}{ Betulinic acid } & $\begin{array}{l}\text { Syzygium jambos (L.) } \\
\text { Alston; Betula } \\
\text { platyphylla Suk. }\end{array}$ & $\begin{array}{l}\text { China, Indochina, } \\
\text { Malaysia, Indonesia; } \\
\text { China, Russia, Mongolia }\end{array}$ & 50, 100, 200 mg/kg, i.g. & $\begin{array}{l}\text { Rat MIRI model (in vivo) (Xia et al., } \\
\text { 2011) }\end{array}$ & $\begin{array}{l}\text { Preventing cardiomyocyte } \\
\text { apoptosis by reducing the release } \\
\text { of } \mathrm{LDH} \text { and } \mathrm{CK}\end{array}$ \\
\hline & & & $5,10,20 \mu \mathrm{M}$ & $\begin{array}{l}\text { H9c2 cardiomyocytes HR model } \\
\text { (in vitro) (Wang D. et al., 2018) }\end{array}$ & $\begin{array}{l}\text { Inhibiting oxidative stress and } \\
\text { apoptosis by Nrf2/HO-1, p38 and } \\
\text { JNK pathways }\end{array}$ \\
\hline \multirow[t]{3}{*}{ Celastrol } & $\begin{array}{l}\text { Tripterygium wilfordii } \\
\text { Hook.F. }\end{array}$ & East Asia & $50 \mathrm{nM}$ & $\begin{array}{l}\text { H9c2 cardiomyocytes HR model } \\
\text { (in vitro) (Li et al., 2017) }\end{array}$ & Inhibiting the activation of NF-кb \\
\hline & & & $0.01,0.1,1 \mu \mathrm{M}$ & $\begin{array}{l}\mathrm{H} 9 \mathrm{c} 2 \text { cardiomyocytes HR model (in } \\
\text { vivo); rat global MIRI injury model (ex } \\
\text { vivo) (Aceros et al., 2019) }\end{array}$ & Modulating HSP90 activity \\
\hline & & & 2, 4, 6 mg/kg, i.g. & $\begin{array}{l}\text { Rat MIRI model (in vivo) (Tong et al., } \\
\text { 2018) }\end{array}$ & $\begin{array}{l}\text { Suppressing apoptosis, } \\
\text { inflammatory and oxidative stress } \\
\text { via PI3K/Akt pathway activation } \\
\text { and HMGB1 inhibition }\end{array}$ \\
\hline \multirow[t]{2}{*}{ Clematichinenoside } & $\begin{array}{l}\text { Clematis chinensis } \\
\text { Osbeck }\end{array}$ & China, Vietnam & $1,10,100 \mu \mathrm{M}$ & $\begin{array}{l}\text { H9c2 cardiomyocytes HR (in vitro) } \\
\text { (Ding et al., 2016) }\end{array}$ & $\begin{array}{l}\text { Inhibiting apoptosis through } \\
\text { mitochondrial mediated apoptotic } \\
\text { signaling pathway }\end{array}$ \\
\hline & & & $\begin{array}{c}0.001,0.01,0.1 \mathrm{mg} / \mathrm{ml} \\
8,16,32 \mathrm{mg} / \mathrm{kg} \text {, i.g.; } 1 \\
10,100 \mu \mathrm{M}\end{array}$ & $\begin{array}{l}\text { Rat global rat MIRI injury model (ex } \\
\text { vivo); rat MIRI model (in vivo); } \\
\text { neonatal rat myocardial cells HR } \\
\text { (in vitro) (Zhang et al., 2013) }\end{array}$ & $\begin{array}{l}\text { Restoring an antioxidant effect by } \\
\text { restoring the balance between } \\
\text { inducible NO synthase and } \\
\text { endothelial NO synthase }\end{array}$ \\
\hline \multirow[t]{2}{*}{ Dioscin } & $\begin{array}{l}\text { Dioscorea } \\
\text { oppositifolia L }\end{array}$ & $\begin{array}{l}\text { China, Japan, South } \\
\text { Korea }\end{array}$ & $0.1,1 \mathrm{nM}$ & $\begin{array}{l}\text { Rat global MIRI injury model (ex vivo) } \\
\text { (Badalzadeh et al., 2014; } \\
\text { Badalzadeh et al., 2015) }\end{array}$ & $\begin{array}{l}\text { Activating mitochondrial } \mathrm{K}_{\mathrm{ATP}} \\
\text { channels and NO system, } \\
\text { attenuating oxidative stress }\end{array}$ \\
\hline & & & 50,100 mg/kg, i.g. & $\begin{array}{l}\text { Rat MIRI model (in vivo) (Wang H. } \\
\text { W. et al., 2018) }\end{array}$ & $\begin{array}{l}\text { Inhibiting inflammation by } \\
\text { regulating p38-MAPK/JNK } \\
\text { pathways and NF-kb pathways }\end{array}$ \\
\hline \multirow[t]{2}{*}{ Glycyrrhizin } & $\begin{array}{l}\text { Glycyrrhiza uralensis } \\
\text { Fisch. }\end{array}$ & China, Russia & 2, 4, 10 mg/kg, i.g. & $\begin{array}{l}\text { Rat MIRI model (in vivo) (Han et al, } \\
\text { 2011; Zhai et al., 2012) }\end{array}$ & $\begin{array}{l}\text { Inhibiting oxidative stress, iNOS } \\
\text { and inflammatory, via HMGB1 and } \\
\text { MAPK expression }\end{array}$ \\
\hline & & & $5,10,20$ mg/kg, i.g. & $\begin{array}{l}\text { Rat MIRI model (in vivo) (Wu et al., } \\
\text { 2015) }\end{array}$ & $\begin{array}{l}\text { Prolonging APD, inhibiting } \mathrm{I}_{\mathrm{Ca}-\mathrm{L}} \text { and } \\
\mathrm{I}_{\text {to }} \text {; blocking phospho-JNK/Bax } \\
\text { pathway }\end{array}$ \\
\hline Ilexsaponin A & $\begin{array}{l}\text { llex pubescens Hook. } \\
\text { et Arn. }\end{array}$ & China & $\begin{array}{c}10,40 \mathrm{mg} / \mathrm{kg} \text {, i.g.; } 10 \\
50,250 \mu \mathrm{M}\end{array}$ & $\begin{array}{l}\text { Rat MIRI model (in vivo); neonatal rat } \\
\text { myocardial cells HR model (in vitro) } \\
\text { (Zhang et al., 2017) }\end{array}$ & Inhibiting apoptotic pathway \\
\hline Ophiopogonin D & $\begin{array}{l}\text { Ophiopogon japonicus } \\
\text { (Linn. f.) Ker-Gawl. }\end{array}$ & $\begin{array}{l}\text { China, Japan, Vietnam, } \\
\text { India }\end{array}$ & 20 mg/kg, i.p. & $\begin{array}{l}\text { Rat MIRI model (in vivo) (Huang } \\
\text { et al., 2018) }\end{array}$ & $\begin{array}{l}\text { Antioxidant and anti-apoptotic } \\
\text { effects }\end{array}$ \\
\hline \multirow[t]{2}{*}{ Sasanquasaponin } & Camellia oleifera Abel & Southern China & $0.1,1,10 \mu \mathrm{M}$ & $\begin{array}{l}\text { Neonatal rat myocardial cells HR } \\
\text { model (in vitro) (Chen et al., 2007) }\end{array}$ & $\begin{array}{l}\text { Inhibiting oxidative stress via } \\
\text { attenuating ROS generation and } \\
\text { increasing antioxidant activities }\end{array}$ \\
\hline & & & $\begin{array}{c}0.1,0.2,0.4 \mathrm{mg} / \mathrm{kg} \\
\text { i.g.; } 0.1 \mu \mathrm{M}\end{array}$ & $\begin{array}{l}\text { Mouse MIRI model (in vivo); adult } \\
\text { mouse myocardial cell HR model } \\
\text { (in vitro) (Lai et al., 2004) }\end{array}$ & $\begin{array}{l}\text { Modulating intracellular } \mathrm{Cl} \text { - } \\
\text { homeostasis and anti-arrhythmia } \\
\text { effects } \\
\quad \text { (Continued on following page) }\end{array}$ \\
\hline
\end{tabular}


TABLE 3 | (Continued) Anti-MIRI effects of other saponins.

\begin{tabular}{|c|c|c|c|c|c|}
\hline Compound & $\begin{array}{l}\text { Major plant } \\
\text { source }\end{array}$ & $\begin{array}{l}\text { Geographical } \\
\text { distribution } \\
\text { of plants }\end{array}$ & Dose/concentration & Models & Mechanism \\
\hline \multirow[t]{2}{*}{ Withaferin A } & Withania Somnifera & India & 1, 5 mg/kg, i.g. & $\begin{array}{l}\text { Rat MIRI model (in vivo) (R. et al., } \\
\text { 2019) }\end{array}$ & $\begin{array}{l}\text { Upregulating AMP-activated } \\
\text { protein kinase-dependent B-cell } \\
\text { lymphoma2 signaling }\end{array}$ \\
\hline & & & $0.1,1 \mu \mathrm{M}$ & $\begin{array}{l}\text { Neonatal rat myocardial cells HR } \\
\text { model (in vitro) (Yan et al., 2018) }\end{array}$ & $\begin{array}{l}\text { Inhibiting apoptosis via activated } \\
\text { Akt-mediated oxidative stress } \\
\text { suppression }\end{array}$ \\
\hline
\end{tabular}

mechanism needs further research. Celastrol, another anti-MIRI saponin, can interact with HSP90, which is similar to Aralia saponins. The structure of celastrol has more unsaturated bonds than oleanolic acid, which indicates its superior antioxidant activity (Aceros et al., 2019). Previous studies have also confirmed that cardiac heart protection mechanism of celastrol involves suppression of oxidative stress, inflammation, and apoptosis via the PI3K/Akt and HMGB1 pathways (Li et al., 2017; Tong et al., 2018). Some studies have suggested that highmobility group box 1 (HMGB1) plays a role in early MIRI, activates the inflammatory response, and promotes cardiomyocyte apoptosis (Tong et al., 2018). Glycyrrhizin, the main active compound in licorice, is a natural HMGB1 inhibitor. Studies have also shown that glycyrrhizin reduces rat MIRI by inhibiting oxidative stress and inflammation (Zhai et al., 2012; Wu et al., 2015).

Furthermore, anti-MIRI saponins also include betulinic acid, clematichinenoside, ilexsaponin A, ophiopogonin D, sasanquasaponin, and withaferin A. Their cardiac protection mechanisms are different, and mainly involve suppression of oxidative stress, inflammation, and apoptosis (Huang et al., 2018; Yan et al., 2018). Based on the current research progress, it can be concluded that the signaling pathways involved in the regulatory mechanism of each saponin are different and that one saponin may affect one or more signaling pathways, indicating the diversity of their therapeutic targets. Saponins with different structures regulate various signaling pathways to achieve cardioprotection. However, the current research on the antiMIRI effect of saponins is not comprehensive, requiring researchers to continue their exploration so as to provide a more theoretical basis and reliable drug candidates for MIRI treatment.

\section{CONCLUSIONS AND PERSPECTIVES}

The targets and anti-MIRI mechanisms of saponins are diverse and mainly include inhibition of oxidative stress, calcium overload, inflammation, and mitochondrial dysfunction. In brief, saponins have a strong antioxidant effect, which in turn helps restore mitochondrial function and intracellular calcium homeostasis, reduces the production of inflammatory factors, and inhibits cardiomyocyte apoptosis, thereby exerting a cardioprotective function (Zhang et al., 2016; Zhang et al., 2017; Yin et al., 2019). Recent studies have revealed the important roles of pyroptosis and ferroptosis in the pathogenesis of MIRI (Wang Z. et al., 2018; Li W. et al., 2020). However, there is no relevant research on the effects of saponins on pyroptosis and ferroptosis. Therefore, the regulatory role of saponins on these new MIRI mechanisms needs to be further studied to completely elucidate the protective mechanism of saponins against MIRI.

Structurally, saponins with vigorous biological activity are mainly oleanolic acid saponins and dammarane-type saponins. Studies have shown that oleanolic acid saponins have a significant regulatory effect on calcium homeostasis (Wang M. et al., 2015), whereas dammarane-type saponins have a more substantial regulatory effect on energy metabolism (Cui et al., 2017). In addition, ginsenosides are more active in dammarane-type saponins, while Aralia saponins are more active in oleanolic acid saponins, which further proves that the unique characteristics of TCM are determined by the structure of its key active components. The occurrence of MIRI is a multi-factor interaction and an extremely complicated process; therefore, multi-target therapy will be the future direction for drug development. Saponins in TCM can act on multiple pathways simultaneously and effectively reduce MIRI (Figure 4). Thus, saponins provide a broad application prospect for the development of highly effective and low-toxicity anti-MIRI drugs.

At present, the study of saponins is still in its initial stage of new structural saponin discovery and data accumulation. Research on the structure-activity relationship of saponins against MIRI, at home and abroad, is still in its infancy. Although the different biological activities and mechanisms of saponins have been gradually elucidated at the molecular level, their clinical applications and saponin-treatment studies for MIRI are limited. Therefore, the systematic summary of the anti-MIRI mechanism of saponins can potentially lay a foundation for detailed study of the anti-MIRI effect and structure-activity relationship of saponins, and thereby aid the development of new anti-MIRI drugs with new mechanisms or targets. A detailed study of the structure-activity relationship of saponins against MIRI would enable the identification of active components or monomers of TCM saponins. This would finally aid the development of drugs with more active and less adverse reactions through chemical modification and artificial synthesis. Thus, the study of saponins will become an important research direction in the development of antiMIRI drugs. 


\section{AUTHOR CONTRIBUTIONS}

Conceptualization, RW, JZ, and MW; writing-original draft preparation, RW; writing-review and editing, MW, GS, and XS; visualization, DW, JY, and JZ; funding acquisition, GS and XS. All authors have read and agreed to the published version of the manuscript.

\section{REFERENCES}

Aceros, H., Der Sarkissian, S., Borie, M., Stevens, L.-M., Mansour, S., and Noiseux, N. (2019). Celastrol-type HSP90 modulators allow for potent cardioprotective effects. Life Sci. 227, 8-19. doi:10.1016/j.lfs.2019.04.025

Alam, M. R., Baetz, D., and Ovize, M. (2015). Cyclophilin D and myocardial ischemia-reperfusion injury: a fresh perspective. J. Mol. Cell. Cardiol. 78, 80-89. doi:10.1016/j.yjmcc.2014.09.026

Alegre, P., Mathias, L., Lourenco, M. A., Santos, P. P. D., Goncalves, A., Fernandes, A. A., et al. (2020). Euterpe oleracea Mart. (Açaí) reduces oxidative stress and improves energetic metabolism in myocardial ischemia-reperfusion injury in rats. Arq. Bras. Cardiol. 114, 78-86. doi:10.36660/abc.20180140

Allam, R., Kumar, S. V. R., Darisipudi, M. N., and Anders, H.-J. (2014). Extracellular histones in tissue injury and inflammation. J. Mol. Med. 92, 465-472. doi:10.1007/s00109-014-1148-z

Aravinthan, A., Kim, J. H., Antonisamy, P., Kang, C. W., Choi, J., Kim, N. S., et al. (2015). Ginseng total saponin attenuates myocardial injury via anti-oxidative and anti-inflammatory properties. J. Ginseng Res. 39, 206-212. doi:10.1016/j. jgr.2014.12.001

Arslan, F., de Kleijn, D. P. V., Timmers, L., Doevendans, P. A., and Pasterkamp, G. (2008). Bridging innate immunity and myocardial ischemia/reperfusion injury: the search for therapeutic targets. Curr. Pharmaceut. Des. 14, 1205-1216. doi:10.2174/138161208784246090

Baba, Y., Higa, J. K., Shimada, B. K., Horiuchi, K. M., Suhara, T., Kobayashi, M., et al. (2018). Protective effects of the mechanistic target of rapamycin against excess iron and ferroptosis in cardiomyocytes. Am. J. Physiol. Heart Circ. Physiol. 314, H659-H668. doi:10.1152/ajpheart.00452.2017

Badalzadeh, R., Yavari, R., and Chalabiani, D. (2015). Mitochondrial ATP-sensitive $\mathrm{K}+$ channels mediate the antioxidative influence of diosgenin on myocardial reperfusion injury in rat hearts. Gen. Physiol. Biophys. 34, 323-329. doi:10.4149/ gpb_2015009

Badalzadeh, R., Yousefi, B., Majidinia, M., and Ebrahimi, H. (2014). Antiarrhythmic effect of diosgenin in reperfusion-induced myocardial injury in a rat model: activation of nitric oxide system and mitochondrial KATP channel. J. Physiol. Sci. 64, 393-400. doi:10.1007/s12576-014-0333-8

Bai, C.-X., Takahashi, K., Masumiya, H., Sawanobori, T., and Furukawa, T. (2004). Nitric oxide-dependent modulation of the delayed rectifier K+current and the L-type Ca2+current by ginsenoside $\mathrm{Re}$, an ingredient of Panaxginseng, in guinea-pig cardiomyocytes. Brit. J. Pharmacol. 142, 567-575. doi:10.1038/sj. bjp.0705814

Bell, R. M., and Yellon, D. M. (2011). There is more to life than revascularization: therapeutic targeting of myocardial ischemia/reperfusion injury. Cardiovascul. Therapeut. 29, 67-79. doi:10.1111/j.1755-5922.2010.00190.x

Bergsbaken, T., Fink, S. L., and Cookson, B. T. (2009). Pyroptosis: host cell death and inflammation. Nat. Rev. Microbiol. 7, 99-109. doi:10.1038/nrmicro2070

Boag, S. E., Andreano, E., and Spyridopoulos, I. (2017). Lymphocyte communication in myocardial ischemia/reperfusion injury. Antioxidants Redox Signal. 26, 660-675. doi:10.1089/ars.2016.6940

Cadenas, S. (2018). ROS and redox signaling in myocardial ischemia-reperfusion injury and cardioprotection. Free Radic. Biol. Med. 117, 76-89. doi:10.1016/j. freeradbiomed.2018.01.024

Chang, L., Shi, R., Wang, X., and Bao, Y. (2020). Gypenoside A protects ischemia/ reperfusion injuries by suppressing miR-143-3p level via the activation of AMPK/Foxol pathway. Biofactors 46, 1-9. doi:10.1002/biof.1601

Chen, H. P., He, M., Huang, Q. R., Liu, D., and Huang, M. (2007). Sasanquasaponin protects rat cardiomyocytes against oxidative stress induced by anoxia-

\section{FUNDING}

This research was funded by Central Public-Interest Scientific Institution Basal Research Fund (No. 2018PT35030 by GS), the National Natural Science Foundation of China (No. 81973514 by GS), the Drug Innovation Major Project (No. 2018ZX09711001-009 by XS) and National Natural Science Foundation of China (No. 81891012 by XS).

reoxygenation injury. Eur. J. Pharmacol. 575, 21-27. doi:10.1016/j.ejphar. 2007.07.043

Chen, J.-K., and Chow, S.-E. (2005). Antioxidants and myocardial ischemia: reperfusion injuries. Chang Gung Med. J. 28, 369-377.

Chen, S., Liu, J., Liu, X., Fu, Y., Zhang, M., Lin, Q., et al. (2011). Panax notoginseng saponins inhibit ischemia-induced apoptosis by activating PI3K/Akt pathway in cardiomyocytes. J. Ethnopharmacol. 137, 263-270. doi:10.1016/j.jep.2011. 05.011

Chen, X., Xu, S., Zhao, C., and Liu, B. (2019). Role of TLR4/NADPH oxidase 4 pathway in promoting cell death through autophagy and ferroptosis during heart failure. Biochem. Biophys. Res. Commun. 516, 37-43. doi:10.1016/j.bbrc 2019.06.015

Cui, Y.-C., Pan, C.-S., Yan, L., Li, L., Hu, B.-H., Chang, X., et al. (2017). Ginsenoside $\mathrm{Rb} 1$ protects against ischemia/reperfusion-induced myocardial injury via energy metabolism regulation mediated by RhoA signaling pathway. Sci. Rep. 7, 44579. doi:10.1038/srep44579

Dai, Y., Wang, S., Chang, S., Ren, D., Shali, S., Li, C., et al. (2020). M2 macrophagederived exosomes carry microRNA-148a to alleviate myocardial ischemia/ reperfusion injury via inhibiting TXNIP and the TLR4/NF- $\kappa \mathrm{B} / \mathrm{NLRP} 3$ inflammasome signaling pathway. J. Mol. Cell. Cardiol. 142, 65-79. doi:10. 1016/j.yjmcc.2020.02.007

Deng, Y., Yang, M., Xu, F., Zhang, Q., Zhao, Q., Yu, H., et al. (2015). Combined salvianolic acid B and ginsenoside Rg1 exerts cardioprotection against ischemia/reperfusion injury in rats. PLoS One. 10, e0135435. doi:10.1371/ journal.pone.0135435

Diaz, I., Calderon-Sanchez, E., Toro, R. D., Avila-Medina, J., de Rojas-de Pedro, E. S., Dominguez-Rodriguez, A., et al. (2017). miR-125a, miR-139 and miR-324 contribute to urocortin protection against myocardial ischemia-reperfusion injury. Sci. Rep. 7, 8898. doi:10.1038/s41598-017-09198-x

Ding, H., Han, R., Chen, X., Fang, W., Liu, M., Wang, X., et al. (2016) Clematichinenoside (AR) attenuates hypoxia/reoxygenation-induced H9c2 cardiomyocyte apoptosis via a mitochondria-mediated signaling pathway. Molecules 21, 583. doi:10.3390/molecules21060683

Dongo, E., Hornyak, I., Benko, Z., and Kiss, L. (2011). The cardioprotective potential of hydrogen sulfide in myocardial ischemia/reperfusion injury (review). Acta Physiol. Hung. 98, 369-381. doi:10.1556/APhysiol.98.2011.4.1

Du, Y., Wang, M., Liu, X., Zhang, J., Xu, X., Xu, H., et al. (2018). Araloside C prevents hypoxia/reoxygenation-induced endoplasmic reticulum stress via increasing heat shock protein 90 in H9c2 cardiomyocytes. Front. Pharmacol. 9, 180. doi:10.3389/fphar.2018.00180

Fang, J., Liu, X., Bolanos, L., Barker, B., Rigolino, C., Cortelezzi, A., et al. (2016). A calcium- and calpain-dependent pathway determines the response to lenalidomide in myelodysplastic syndromes. Nat. Med. 22, 727-734. doi:10. 1038/nm.4127

Fang, X., Wang, H., Han, D., Xie, E., Yang, X., Wei, J., et al. (2019). Ferroptosis as a target for protection against cardiomyopathy. Proc. Natl. Acad. Sci. U. S. A. 116, 2672-2680.

Garcia-Dorado, D., Rodríguez-Sinovas, A., Ruiz-Meana, M., and Inserte, J. (2014) Protection against myocardial ischemia-reperfusion injury in clinical practice. Rev. Esp. Cardiol. 67, 394-404. doi:10.1016/j.rec.2014.01.010

Grueter, C. E., Colbran, R. J., and Anderson, M. E. (2007). CaMKII, an emerging molecular driver for calcium homeostasis, arrhythmias, and cardiac dysfunction. J. Mol. Med. 85, 5-14. doi:10.1007/s00109-006-0125-6

Han, X.-H., Liu, P., Zhang, Y.-Y., Zhang, N., Chen, F.-R., and Cai, J.-F. (2011) Astragaloside IV regulates expression of ATP-sensitive potassium channel subunits after ischemia-reperfusion in rat ventricular cardiomyocytes. J. Tradit. Chin. Med. 31, 321-326. doi:10.1016/s0254-6272(12)60012-0 
He, K., Yan, L., Pan, C.-S., Liu, Y.-Y., Cui, Y.-C., Hu, B.-H., et al. (2014). ROCKdependent ATP5D modulation contributes to the protection of notoginsenoside NR1 against ischemia-reperfusion-induced myocardial injury. Am. J. Physiol. Heart Circ. Physiol. 307, 1764-1776. doi:10.1152/ ajpheart.00259.2014.-Cardiac

Hu, Y., Ip, F. C., Fu, G., Pang, H., Ye, W., and Ip, N. Y. (2010). Dammarane saponins from Gynostemma pentaphyllum. Phytochemistry 71, 1149-1157. doi:10.1016/j.phytochem.2010.04.003

Huang, X., Wang, Y., Wang, Y., Yang, L., Wang, J., and Gao, Y. (2018). Ophiopogonin D reduces myocardial ischemia-reperfusion injury via upregulating CYP2J3/EETs in rats. Cell. Physiol. Biochem. 49, 1646-1658. doi: $10.1159 / 000493500$

Ibanez, B., Heusch, G., Ovize, M., and Van de Werf, F. (2015). Evolving therapies for myocardial ischemia/reperfusion injury. J. Am. Coll. Cardiol. 65, 1454-1471. doi:10.1016/j.jacc.2015.02.032

Jia, C., Chen, H., Zhang, J., Zhou, K., Zhuge, Y., Niu, C., et al. (2019). Role of pyroptosis in cardiovascular diseases. Int. Immunopharm. 67, 311-318. doi:10. 1016/j.intimp.2018.12.028

Jiang, T., You, H., You, D., Zhang, L., Ding, M., and Yang, B. (2020). A miR-1275 mimic protects myocardiocyte apoptosis by regulating the Wnt/NF- $\mathrm{kB}$ pathway in a rat model of myocardial ischemia-reperfusion-induced myocardial injury. Mol. Cell. Biochem. 466, 129-137. doi:10.1007/s11010-020-03695-w

Lai, Z.-F., Shao, Z., Chen, Y.-Z., He, M., Huang, Q., and Nishi, K. (2004). Effects of Sasanquasaponin on ischemia and reperfusion injury in mouse heart. $J$. Pharmacol. Sci. 94, 313-324. doi:10.1254/jphs.94.313

Leo, M. D., Sanogo, R., Tommasi, N. D., and Braca, A. (2007). Oleanane saponins from stylosanthes erecta. J. Nat. Prod. 70, 979-983. doi:10.1021/np0700671

Lesnefsky, E. J., Chen, Q., Tandler, B., and Hoppel, C. L. (2017). Mitochondrial dysfunction and myocardial ischemia-reperfusion: implications for novel therapies. Annu. Rev. Pharmacol. Toxicol. 57, 535-565. doi:10.1146/annurevpharmtox-010715-103335

Li, C. Y., Yang, P., Jiang, Y. L., Lin, Z., Pu, Y. W., Xie, L. Q., et al. (2020). Ginsenoside $\mathrm{Rb} 1$ attenuates cardiomyocyte apoptosis induced by myocardial ischemia reperfusion injury through mTOR signal pathway. Biomed. Pharmacother. 125, 109913. doi:10.1016/j.biopha.2020.109913

Li, F., Zhao, H., Han, Z., Wang, R., Tao, Z., Fan, Z., et al. (2019). Xuesaitong may protect against ischemic stroke by modulating microglial phenotypes and inhibiting neuronal cell apoptosis via the STAT3 signaling pathway. CNS Neurol. Disord. - Drug Targets. 18, 115-123. doi:10.2174/ 1871527317666181114140340

Li, G., Qian, W., and Zhao, C. (2016). Analyzing the anti-ischemia-reperfusion injury effects of ginsenoside Rb1 mediated through the inhibition of p38a MAPK. Can. J. Physiol. Pharmacol. 94, 97-103. doi:10.1139/cjpp-20140164

Li, L., Pan, C. S., Yan, L., Cui, Y. C., Liu, Y. Y., Mu, H. N., et al. (2018). Ginsenoside Rg1 ameliorates rat myocardial ischemia-reperfusion injury by modulating energy metabolism pathways. Front. Physiol. 9, 78. doi:10.3389/fphys.2018. 00078

Li, S., Chen, G., and Li, R. A. (2013). Calcium signalling of human pluripotent stem cell-derived cardiomyocytes. J. Physiol. (Lond.). 591, 5279-5290. doi:10.1113/ jphysiol.2013.256495

Li, W., Li, W., Leng, Y., Xiong, Y., and Xia, Z. (2020). Ferroptosis is involved in diabetes myocardial ischemia/reperfusion injury through endoplasmic reticulum stress. DNA Cell Biol. 39, 210-225. doi:10.1089/dna.2019.5097

Li, X., Wu, N., Zou, L., and Jia, D. (2017). Protective effect of celastrol on myocardial ischemia-reperfusion injury. Anatol. J. Cardiol. 18, 384-390. doi:10.14744/AnatolJCardiol.2017.7866

Lim, K. H., Lim, D. J., and Kim, J. H. (2013). Ginsenoside-Re ameliorates ischemia and reperfusion injury in the heart: a hemodynamics approach. J. Ginseng. Res. 37, 283-292. doi:10.5142/jgr.2013.37.283

Liu, K., Li, M., Ren, X., You, Q.-S., Wang, F., Wang, S., et al. (2019). Huang Qi Tong Bi decoction attenuates myocardial ischemia-reperfusion injury via HMGB1/ TLR/NF-. Mediat. Inflamm. 2019, 8387636. doi:10.1155/2019/8387636

Liu, Q., Li, J., Wang, J., Li, J., Janicki, J. S., and Fan, D. (2013). Effects and mechanisms of Chinese herbal medicine in ameliorating myocardial ischemiareperfusion injury. Evid. Base Compl. Alternative Med. 2013, 1-14. doi:10.1155/ 2013/925625
Liu, X.-W., Lu, M.-K., Zhong, H.-T., Wang, L.-H., and Fu, Y.-P. (2019). Panax notoginseng saponins attenuate myocardial ischemia-reperfusion injury through the HIF-1a/BNIP3 pathway of autophagy. J. Cardiovasc. Pharmacol. 73, 92-99. doi:10.1097/FJC.0000000000000640

Luo, Y., Wan, Q., Xu, M., Zhou, Q., Chen, X., and Yin, D., et al. (2019). Nutritional preconditioning induced by astragaloside on isolated hearts and cardiomyocytes against myocardial ischemia injury via improving Bcl-2mediated mitochondrial function. Chem. Biol. Interact. 309, 108723. doi:10. 1016/j.cbi.2019.06.036

Ma, L., Liu, H., Xie, Z., Yang, S., Xu, W., and Hou, J., et al. (2014). Ginsenoside Rb3 protects cardiomyocytes against ischemia-reperfusion injury via the inhibition of JNK-mediated NF-kappaB pathway: a mouse cardiomyocyte model. PLoS One 9, e103628. doi:10.1371/journal.pone.0103628

MacLennan, D. H., and Kranias, E. G. (2003). Phospholamban: a crucial regulator of cardiac contractility. Nat. Rev. Mol. Cell Biol. 4, 566-577. doi:10.1038/ nrm1151

Makhdoumi, P., Roohbakhsh, A., and Karimi, G. (2016). MicroRNAs regulate mitochondrial apoptotic pathway in myocardial ischemia-reperfusion-injury. Biomed. Pharmacother. 84, 1635-1644. doi:10.1016/j.biopha.2016.10.073

Matsushima, S., Tsutsui, H., and Sadoshima, J. (2014). Physiological and pathological functions of NADPH oxidases during myocardial ischemiareperfusion. Trends Cardiovasc. Med. 24, 202-205. doi:10.1016/j.tcm.2014. 03.003

Moos, M. P. W., and Funk, C. D. (2008). Endothelial cysteinyl leukotriene 2 receptor expression and myocardial ischemia reperfusion injury. Trends Cardiovasc. Med. 18, 268-273. doi:10.1016/j.tcm.2008.11.009

Ney, P. A. (2015). Mitochondrial autophagy: origins, significance, and role of BNIP3 and NIX. Biochim. Biophys. Acta. 1853, 2775-2783. doi:10.1016/j. bbamcr.2015.02.022

Ohtsuka, M., Takano, H., Suzuki, M., Zou, Y., Akazawa, H., Tamagawa, M., et al. (2004). Role of $\mathrm{Na}+-\mathrm{Ca} 2+$ exchanger in myocardial ischemia/reperfusion injury: evaluation using a heterozygous $\mathrm{Na}+-\mathrm{Ca} 2+$ exchanger knockout mouse model. Biochem. Biophys. Res. Commun. 314, 849-853. doi:10.1016/j.bbrc.2003. 12.165

Ong, S. B., Samangouei, P., Kalkhoran, S. B., and Hausenloy, D. J. (2015). The mitochondrial permeability transition pore and its role in myocardial ischemia reperfusion injury. J. Mol. Cell. Cardiol. 78, 23-34. doi:10.1016/j.yjmcc.2014.11.005

Paradies, G., Paradies, V., Ruggiero, F. M., and Petrosillo, G. (2018). Mitochondrial bioenergetics and cardiolipin alterations in myocardial ischemia-reperfusion injury: implications for pharmacological cardioprotection. Am. J. Physiol. Heart Circ. Physiol. 315, H1341-H1352. doi:10.1152/ajpheart.00028.2018

Pei, Y. H., Chen, J., Wu, X., He, Y., Qin, W., He, S. Y., et al. (2020). LncRNA PEAMIR inhibits apoptosis and inflammatory response in PM2.5 exposure aggravated myocardial ischemia/reperfusion injury as a competing endogenous RNA of miR-29b-3p. Nanotoxicology 14, 638-653. doi:10.1080/17435390.2020. 1731857

Peng, J. J., Song, W. T., Yao, F., Zhang, X., Peng, J., Luo, X. J., et al. (2020). Involvement of regulated necrosis in blinding diseases: focus on necroptosis and ferroptosis. Exp. Eye Res. 191, 107922. doi:10.1016/j.exer.2020.107922

Qin, L., Fan, S., Jia, R., and Liu, Y. (2018). Ginsenoside Rg1 protects cardiomyocytes from hypoxia-induced injury through the PI3K/AKT/mTOR pathway. Pharmazie. 73, 349-355. doi:10.1691/ph.2018.8329

Qiu, Z., Lei, S., Zhao, B., Wu, Y., Su, W., Liu, M., et al. (2017). NLRP3 inflammasome activation-mediated pyroptosis aggravates myocardial ischemia/reperfusion injury in diabetic rats. Oxid Med Cell Longev. 1-17. doi: $10.1155 / 2017 / 9743280$

R, G., L, G., WB, L., Z, Y., D, X., and E, G., et al. (2019). Withaferin A prevents myocardial ischemia/reperfusion injury by upregulating AMP-activated protein kinase-dependent B-cell lymphoma2 signaling. Circ. J. 83, 1726-1736. doi:10.1253/circj.CJ-18-1391

Raivio, P., Lassila, R., and Petaja, J. (2009). Thrombin in myocardial ischemiareperfusion during cardiac surgery. Ann. Thorac. Surg. 88, 318-325. doi:10. 1016/j.athoracsur.2008.12.097

Ruan, Z., Wang, S., Yu, W., and Deng, F. (2019). LncRNA MALAT1 aggravates inflammation response through regulating PTGS2 by targeting miR-26b in myocardial ischemia-reperfusion injury. Int. J. Cardiol. 288, 122. doi:10.1016/j. ijcard.2019.04.015 
Russo, I., Penna, C., Musso, T., Popara, J., Alloatti, G., Cavalot, F., et al. (2017). Platelets, diabetes and myocardial ischemia/reperfusion injury. Cardiovasc. Diabetol. 16, 71. doi:10.1186/s12933-017-0550-6

Sandanger, Ø., Gao, E., Ranheim, T., Bliksøen, M., Kaasbøll, O. J., Alfsnes, K., et al. (2016). NLRP3 inflammasome activation during myocardial ischemia reperfusion is cardioprotective. Biochem. Biophys. Res. Commun. 469, 1012-1020. doi:10.1016/j.bbrc.2015.12.051

Schanze, N., Bode, C., and Duerschmied, D. (2019). Platelet contributions to myocardial ischemia/reperfusion injury. Front. Immunol. 10, 1260. doi:10. 3389/fimmu.2019.01260

Shi, Y., Han, B., Yu, X., Qu, S., and Sui, D. (2011). Ginsenoside Rb3 ameliorates myocardial ischemia-reperfusion injury in rats. Pharm. Biol. 49, 900-906. doi:10.3109/13880209.2011.554845

Shin, B. K., Kwon, S. W., and Park, J. H. (2015). Chemical diversity of ginseng saponins from Panax ginseng. J. Ginseng Res. 39, 287-298. doi:10.1016/j.jgr. 2014.12.005

Shirakabe, A., Zhai, P., Ikeda, Y., Saito, T., Maejima, Y., Hsu, C. P., et al. (2016). Drp1-dependent mitochondrial autophagy plays a protective role against pressure overload-induced mitochondrial dysfunction and heart failure. Circulation. 133, 1249-1263. doi:10.1161/CIRCULATIONAHA.115.020502

Singhal, A. K., Symons, J. D., Boudina, S., Jaishy, B., and Shiu, Y.-T. (2010). Role of endothelial cells in myocardial ischemia-reperfusion injury. Vasc. Dis. Prev. 7, 1-14. doi:10.2174/1874120701007010001

Sumneang, N., Siri-Angkul, N., Kumfu, S., Chattipakorn, S. C., and Chattipakorn, N. (2020). The effects of iron overload on mitochondrial function, mitochondrial dynamics, and ferroptosis in cardiomyocytes. Arch. Biochem. Biophys. 680, 108241. doi:10.1016/j.abb.2019.108241

Tian, L., Cao, W., Yue, R., Yuan, Y., Guo, X., Qin, D., et al. (2019). Pretreatment with Tilianin improves mitochondrial energy metabolism and oxidative stress in rats with myocardial ischemia/reperfusion injury via AMPK/SIRT1/PGC-1 alpha signaling pathway. J. Pharmacol. Sci. 139, 352-360. doi:10.1016/j.jphs. 2019.02.008

Tian, Y., Du, Y. Y., Shang, H., Wang, M., Sun, Z. H., Wang, B. Q., et al. (2017). Calenduloside $\mathrm{E}$ analogues protecting $\mathrm{H} 9 \mathrm{c} 2$ cardiomyocytes against $\mathrm{H} 2 \mathrm{O} 2$ induced apoptosis: design, synthesis and biological evaluation. Front. Pharmacol. 8, 862. doi:10.3389/fphar.2017.00862

Toldo, S., Mauro, A. G., Cutter, Z., and Abbate, A. (2018). Inflammasome, pyroptosis, and cytokines in myocardial ischemia-reperfusion injury. Am. J. Physiol. Heart Circ. Physiol. 315, 1553-1568. doi:10.1152/ajpheart.00158.2018

Tong, M., and Sadoshima, J. (2016). Mitochondrial autophagy in cardiomyopathy. Curr. Opin. Genet. Dev. 38, 8-15. doi:10.1016/j.gde.2016.02.006

Tong, S., Zhang, L., Joseph, J., and Jiang, X. (2018). Celastrol pretreatment attenuates rat myocardial ischemia/reperfusion injury by inhibiting high mobility group box 1 protein expression via the PI3K/Akt pathway. Biochem. Biophys. Res. Commun. 497, 843-849. doi:10.1016/j.bbrc.2018.02.121

Tu, L., Pan, C. S., Wei, X. H., Yan, L., Liu, Y. Y., Fan, J. Y., et al. (2013). Astragaloside IV protects heart from ischemia and reperfusion injury via energy regulation mechanisms. Microcirculation. 20, 736-747. doi:10.1111/ micc. 12074

Turer, A. T., and Hill, J. A. (2010). Pathogenesis of myocardial ischemiareperfusion injury and rationale for therapy. Am. J. Cardiol. 106, 360-368. doi:10.1016/j.amjcard.2010.03.032

Verkhratsky, A., and Parpura, V. (2014). Calcium signalling and calcium channels: evolution and general principles. Eur. J. Pharmacol. 739, 1-3. doi:10.1016/j. ejphar.2013.11.013

Vinten-Johansen, J., Jiang, R., Reeves, J. G., Mykytenko, J., Deneve, J., and Jobe, L. J. (2007). Inflammation, proinflammatory mediators and myocardial ischemia-reperfusion injury. Hematol. Oncol. Clin. N. Am. 21, 123-145. doi:10.1016/j.hoc.2006.11.010

Wang, D., Chen, T., and Liu, F. (2018). Betulinic acid alleviates myocardial hypoxia/reoxygenation injury via inducing Nrf2/HO-1 and inhibiting p38 and JNK pathways. Eur. J. Pharmacol. 838, 53-59. doi:10.1016/j.ejphar.2018. 08.024

Wang, H. W., Liu, H. J., Cao, H., Qiao, Z. Y., and Xu, Y. W. (2018). Diosgenin protects rats from myocardial inflammatory injury induced by ischemiareperfusion. Med. Sci. Monit. 24, 246-253. doi:10.12659/msm.907745

Wang, J. R., Zhou, H., Yi, X. Q., Jiang, Z. H., and Liu, L. (2012). Total ginsenosides of Radix Ginseng modulates tricarboxylic acid cycle protein expression to enhance cardiac energy metabolism in ischemic rat heart tissues. Molecules. 17, 12746-12757. doi:10.3390/molecules 171112746

Wang, M., Sun, G. B., Zhang, J. Y., Luo, Y., Yu, Y. L., Xu, X. D., et al. (2015). Elatoside $\mathrm{C}$ protects the heart from ischaemia/reperfusion injury through the modulation of oxidative stress and intracellular $\mathrm{Ca}(2)(+)$ homeostasis. Int. J. Cardiol. 185, 167-176. doi:10.1016/j.ijcard.2015.03.140

Wang, M., Tian, Y., Du, Y. Y., Sun, G. B., Xu, X. D., Jiang, H., et al. (2017). Protective effects of Araloside $\mathrm{C}$ against myocardial ischaemia/reperfusion injury: potential involvement of heat shock protein 90. J. Cell Mol. Med. 21, 1870-1880. doi:10.1111/jcmm.13107

Wang, M., Wang, R., Xie, X., Sun, G., and Sun, X. (2019). Araloside C protects $\mathrm{H} 9 \mathrm{c} 2$ cardiomyoblasts against oxidative stress via the modulation of mitochondrial function. Biomed. Pharmacother. 117, 109143. doi:10.1016/j. biopha.2019.109143

Wang, M., Xu, X., Xu, H., Wen, F., Zhang, X., Sun, H., et al. (2014). Effect of the total saponins of Aralia elata (Miq) Seem on cardiac contractile function and intracellular calcium cycling regulation. J. Ethnopharmacol. 155, 240-247. doi:10.1016/j.jep.2014.05.024

Wang, R., Yang, M., Wang, M., Liu, X., Xu, H., Xu, X., et al. (2018). Total saponins of Aralia elata (Miq) Seem alleviate calcium homeostasis imbalance and endoplasmic reticulum stress-related apoptosis induced by myocardial ischemia/reperfusion injury. Cell. Physiol. Biochem. 50, 28-40. doi:10.1159/000493954

Wang, Y., Hu, Z., Sun, B., Xu, J., Jiang, J., and Luo, M. (2015). Ginsenoside Rg3 attenuates myocardial ischemia/reperfusion injury via Akt/endothelial nitric oxide synthase signaling and the Bcell lymphoma/Bcell lymphomaassociated X protein pathway. Mol. Med. Rep. 11, 4518-4524. doi:10.3892/mmr.2015.3336

Wang, Y., Li, X., Wang, X., Lau, W., Wang, Y., Xing, Y., et al. (2013). Ginsenoside $\mathrm{Rd}$ attenuates myocardial ischemia/reperfusion injury via Akt/GSK-3b signaling and inhibition of the mitochondria-dependent apoptotic pathway. PLoS One. 8, e70956. doi:10.1371/journal.pone.0070956.g001

Wang, Z., Yang, F., Jiang, Y., Wang, R., Chen, X., Lv, J., et al. (2018). Role of pyroptosis in normal cardiac response to calorie restriction and starvation. Biochem. Biophys. Res. Commun. 495, 1122-1128. doi:10.1016/j.bbrc.2017.11.144

Wu, C., Lu, W., Zhang, Y., Zhang, G., Shi, X., Hisada, Y., et al. (2019). Inflammasome activation triggers blood clotting and host death through pyroptosis. Immunity. 50, 1401-1411. doi:10.1016/j.immuni.2019.04.003

Wu, H. J., Yang, J. Y., Jin, M., Wang, S. Q., Wu, D. L., Liu, Y. N., et al. (2015). Glycyrrhetinic acid protects the heart from ischemia/reperfusion injury by attenuating the susceptibility and incidence of fatal ventricular arrhythmia during the reperfusion period in the rat hearts. Cell. Physiol. Biochem. 36, 741-752. doi:10.1159/000430134

Wu, S., Chang, G., Gao, L., Jiang, D., Wang, L., Li, G., et al. (2018). Trimetazidine protects against myocardial ischemia/reperfusion injury by inhibiting excessive autophagy. J. Mol. Med. (Berl.). 96, 791-806. doi:10.1007/s00109-018-1664-3

Xia, R., Zhao, B., Wu, Y., Hou, J. B., Zhang, L., Xu, J. J., et al. (2011). Ginsenoside $\mathrm{Rb} 1$ preconditioning enhances eNOS expression and attenuates myocardial ischemia/reperfusion injury in diabetic rats. J. Biomed. Biotechnol. 767930. doi:10.1155/2011/767930

Xie, Y., Hou, W., Song, X., Yu, Y., Huang, J., Sun, X., et al. (2016). Ferroptosis process and function. Cell Death Differ. 23, 369-379. doi:10.1038/cdd.2015.158

Xiong, W., Yan, Q., Chen, H., and Qian, J., 2019. Insight into long noncoding RNAmiRNA-mRNA axes in myocardial ischemia-reperfusion injury: the implications for mechanism and therapy. Epigenomics. 11, 1733-1748. doi:10.2217/epi-2019-0119

Xu, X. L., Chen, X. J., Ji, H., Li, P., Bian, Y. Y., Yang, D., et al. (2008). Astragaloside IV improved intracellular calcium handling in hypoxia-reoxygenated cardiomyocytes via the sarcoplasmic reticulum Ca-ATPase. Pharmacology. 81, 325-332. doi:10.1159/000121335

Yan, J., Duan, J., Wu, X., Guo, C., Yin, Y., Zhu, Y., et al. (2015). Total saponins from Aralia taibaiensis protect against myocardial ischemia/reperfusion injury through AMPK pathway. Int. J. Mol. Med. 36, 1538-1546. doi:10.3892/ ijmm.2015.2391

Yan, Z., Guo, R., Gan, L., Lau, W. B., Cao, X., Zhao, J., et al. (2018). Withaferin A inhibits apoptosis via activated Akt-mediated inhibition of oxidative stress. Life Sci. 211, 91-101. doi:10.1016/j.lfs.2018.09.020

Yang, F., Qin, Y., Lv, J., Wang, Y., Che, H., Chen, X., et al. (2018). Silencing long non-coding RNA Kcnqlot1 alleviates pyroptosis and fibrosis in diabetic cardiomyopathy. Cell Death Dis. 9, 1000. doi:10.1038/s41419. 018-1029-4 
Yin, B., Hou, X. W., and Lu, M. L. (2019). Astragaloside IV attenuates myocardial ischemia/reperfusion injury in rats via inhibition of calcium-sensing receptormediated apoptotic signaling pathways. Acta Pharmacol. Sin. 40, 599-607. doi:10.1038/s41401-018-0082-y

Yu, H., Shi, L., Qi, G., Zhao, S., Gao, Y., and Li, Y. (2016a). Gypenoside protects cardiomyocytes against ischemia-reperfusion injury via the inhibition of mitogen-activated protein kinase mediated nuclear factor kappa B pathway in vitro and in vivo. Front. Pharmacol. 7, 148. doi:10.3389/fphar.2016.00148

Yu, H., Zhang, H., Zhao, W., Guo, L., Li, X., and Li, Y., et al. (2016b). Gypenoside protects against myocardial ischemia-reperfusion injury by inhibiting cardiomyocytes apoptosis via inhibition of CHOP pathway and activation of PI3K/Akt pathway in vivo and in vitro. Cell. Phys. Biochem. 39, 123-136. doi:10. 1159/000445611

Yu, Y., Sun, G., Luo, Y., Wang, M., Chen, R., Zhang, J., et al. (2016c). Cardioprotective effects of Notoginsenoside R1 against ischemia/reperfusion injuries by regulating oxidative stress- and endoplasmic reticulum stressrelated signaling pathways. Sci. Rep. 6, 21730. doi:10.1038/srep21730

Yuan, C., Wang, H., and Yuan, Z. (2019). Ginsenoside Rg1 inhibits myocardial ischaemia and reperfusion injury via HIF-1 a-ERK signalling pathways in a diabetic rat model. Pharmazie. 74, 157-162. doi:10.1691/ph.2019.8858

Yumnamcha, T., Devi, T. S., and Singh, L. P. (2019). Auranofin mediates mitochondrial dysregulation and inflammatory cell death in human retinal pigment epithelial cells: implications of retinal neurodegenerative diseases. Front. Neurosci. 13, 1065. doi:10.3389/fnins.2019.01065

Zebiri, I., Haddad, M., Duca, L., Harakat, D., Cabanillas, B., and Paloque, L., et al. (2016). Zebiriosides A-L, oleanane saponins from the roots of Dendrobangia boliviana. Phytochemistry 130, 262-272. doi:10.1016/j. phytochem.2016.06.006

Zeng, X., Li, J., and Li, Z. (2015). Ginsenoside Rd mitigates myocardial ischemiareperfusion injury via Nrf2 HO-1 signaling pathway. Int. J. Clin. Exp. Med. 15, 14497-14504. doi:1940-5901/IJCEM0009419

Zhai, C. L., Zhang, M. Q., Zhang, Y., Xu, H. X., Wang, J. M., An, G. P., et al. (2012). Glycyrrhizin protects rat heart against ischemia-reperfusion injury through blockade of HMGB1-dependent phospho-JNK/Bax pathway. Acta Pharmacol. Sin. 33, 1477-1487. doi:10.1038/aps.2012.112

Zhang, L. P., Jiang, Y. C., Yu, X. F., Xu, H. L., Li, M., Zhao, X. Z., et al. (2016). Ginsenoside Rg3 improves cardiac function after myocardial ischemia/ reperfusion via attenuating apoptosis and inflammation. Evid. Based. Complement. Alternat. Med. 2016, 6967853. doi:10.1155/2016/6967853

Zhang, R., Fang, W., Han, D., Sha, L., Wei, J., and Liu, L., et al. (2013). Clematichinenoside attenuates myocardial infarction in ischemia/reperfusion injury both in vivo and in vitro. Planta. Med. 79, 1289-1297. doi:10.1055/s0033-1350671

Zhang, S. W., Liu, Y., Wang, F., Qiang, J., Liu, P., Zhang, J., et al. (2017). Ilexsaponin A attenuates ischemia-reperfusion-induced myocardial injury through antiapoptotic pathway. PLoS One. 12, e0170984. doi:10.1371/journal.pone.0170984

Zhao, D., Yang, J., and Yang, L. (2017). Insights for oxidative stress and mTOR signaling in myocardial ischemia/reperfusion injury under diabetes. Oxid. Med. Cell. Longev. 2017, 1-12. doi:10.1155/2017/6437467

Zhao, X., Zhang, F., and Wang, Y. (2017). Proteomic analysis reveals Xuesaitong injection attenuates myocardial ischemia/reperfusion injury by elevating pyruvate dehydrogenase-mediated aerobic metabolism. Mol. Biosyst. 13, 1504-1511. doi:10.1039/c7mb00140a

Zheng, Q., Bao, X. Y., Zhu, P. C., Tong, Q., Zheng, G. Q., and Wang, Y. (2017). Ginsenoside Rb1 for myocardial ischemia/reperfusion injury: preclinical evidence and possible mechanisms. Oxid. Med. Cell Longev. 2017, 6313625. doi: $10.1155 / 2017 / 6313625$

Zhou, T., Chuang, C.-C., and Zuo, L. (2015). Molecular characterization of reactive oxygen species in myocardial ischemia-reperfusion injury. BioMed. Res. Int. 2015, 864946. doi:10.1155/2015/864946

Zhu, S., Xu, T., Luo, Y., Zhang, Y., Xuan, H., Ma, Y., et al. (2017). Luteolin enhances sarcoplasmic reticulum Ca2+-ATPase activity through p38 MAPK signaling thus improving rat cardiac function after ischemia/reperfusion. Cell. Physiol. Biochem. 41, 999-1010. doi:10.1159/000460837

ZL, Z., Y, F., and ML, L. (2012). Ginsenoside Rg1 inhibits autophagy in H9c2 cardiomyocytes exposed to hypoxia/reoxygenation. Mol. Cell. Biochem. 365, 243-250. doi:10.1007/s11010-012-1265-3

Zong, L., and Wang, W. (2020). CircANXA2 promotes myocardial apoptosis in myocardial ischemia-reperfusion injury via inhibiting miRNA-133 expression. BioMed. Res. Int. 2020, 8590861. doi:10.1155/2020/8590861

Conflict of Interest: The authors declare that the research was conducted in the absence of any commercial or financial relationships that could be construed as a potential conflict of interest.

Copyright (c) 2021 Wang, Wang, Zhou, Wu, Ye, Sun and Sun. This is an open-access article distributed under the terms of the Creative Commons Attribution License (CC $B Y$ ). The use, distribution or reproduction in other forums is permitted, provided the original author(s) and the copyright owner(s) are credited and that the original publication in this journal is cited, in accordance with accepted academic practice. No use, distribution or reproduction is permitted which does not comply with these terms. 